\title{
Fabrication of biocompatible porous scaffolds based on hydroxyapatite/collagen/chitosan composite for restoration of defected maxillofacial mandible bone
}

\author{
Md Shaifur Rahman ${ }^{1} @$. Md Masud Rana ${ }^{2} \cdot$ Lucas-Sebastian Spitzhorn $^{1} \cdot$ Naznin Akhtar ${ }^{3} \cdot$ Md Zahid Hasan $^{2}$. \\ Naiyyum Choudhury ${ }^{4} \cdot$ Tanja Fehm $^{5}$. Jan T. Czernuszka ${ }^{6}$. James Adjaye ${ }^{1} \cdot$ Sikder M. Asaduzzaman $^{2}$
}

Received: 23 January 2019 / Accepted: 29 April 2019 / Published online: 29 May 2019

(c) The Author(s) 2019

\begin{abstract}
Fabrication of scaffolds from biomaterials for restoration of defected mandible bone has attained increased attention due to limited accessibility of natural bone for grafting. Hydroxyapatite (Ha), collagen type 1 (Col1) and chitosan (Cs) are widely used biomaterials which could be fabricated as a scaffold to overcome the paucity of bone substitutes. Here, rabbit Col1, shrimp Cs and bovine Ha were extracted and characterized with respect to physicochemical properties. Following the biocompatibility, degradability and cytotoxicity tests for $\mathrm{Ha}$, Col1 and Cs a hydroxyapatite/collagen/chitosan (Ha.Col1.Cs) scaffold was fabricated using thermally induced phase separation technique. This scaffold was cross-linked with (1) either glutaraldehyde (GTA), (2) de-hydrothermal treatment (DTH), (3) irradiation (IR) and (4) 2-hydroxyethyl methacrylate (HEMA), resulting in four independent types (Ha.Col1·Cs-GTA, Ha.Col1·Cs-IR, Ha.Col1·Cs-DTH and Ha.Col1·Cs-HEMA). The developed composite scaffolds were porous with 3D interconnected fiber microstructure. However, Ha.Col1.Cs-IR and Ha.Col1.Cs-GTA showed better hydrophilicity and biodegradability. All four scaffolds showed desirable blood biocompatibility without cytotoxicity for brine shrimp. In vitro studies in the presence of human amniotic fluid-derived mesenchymal stem cells revealed that Ha.Col1.Cs-IR and Ha.Col1.Cs-DHT scaffolds were non-cytotoxic and compatible for cell attachment, growth and mineralization. Further, grafting of Ha.Col1·Cs-IR and Ha.Col1.Cs-DHT was performed in a surgically created non-load-bearing rabbit maxillofacial mandible defect model. Histological and radiological observations indicated the restoration of defected bone. Ha.Col1.Cs-IR and Ha.Col1.Cs-DHT could be used as an alternative treatment in bone defects and may contribute to further development of scaffolds for bone tissue engineering.
\end{abstract}

Keywords Hydroxyapatite $\cdot$ Collagen $\cdot$ Chitosan $\cdot$ Scaffold $\cdot$ Biocompatibility $\cdot$ AF-MSCs $\cdot$ Mandible bone defect $\cdot$ Bone tissue engineering

Electronic supplementary material The online version of this article (https://doi.org/10.1007/s40204-019-0113-x) contains supplementary material, which is available to authorized users.

Sikder M. Asaduzzaman sikderasad@yahoo.com

1 Institute for Stem Cell Research and Regenerative Medicine, Medical Faculty, Heinrich-Heine-Universität Düsseldorf, 40225 Düsseldorf, Germany

2 Institute of Tissue Banking and Biomaterial Research, Atomic Energy Research Establishment, 1349 Dhaka, Bangladesh

3 School of Medicine, Geelong Waurn Ponds Campus, Deakin University, Waurn Ponds, Victoria 3217, Australia

$\begin{array}{ll}\text { Abbreviations } \\ \text { Ha } & \text { Hydroxyapatite } \\ \text { Col1 } & \text { Collagen type } 1 \\ \text { Cs } & \text { Chitosan } \\ \text { SEM } & \text { Scanning electron microscopy }\end{array}$

4 Bangladesh Atomic Energy Regulatory Authority, Dhaka, Bangladesh

5 Department of Obstetrics and Gynaecology, Medical Faculty, Heinrich-Heine-Universität Düsseldorf, 40225 Düsseldorf, Germany

6 Department of Materials, University of Oxford, Oxford OX1 3PH, UK 


$\begin{array}{ll}\text { HaCol1Cs } & \text { Hydroxyapatite-collagen type 1-chitosan } \\ \text { XRD } & \text { X-ray diffraction } \\ \text { XRF } & \text { X-ray fluorescence spectroscopy } \\ \text { HPLC } & \text { High-performance liquid chromatography } \\ \text { SDS-PAGE } & \begin{array}{l}\text { Sodium dodecyl sulfate polyacrylamide gel } \\ \text { electrophoresis }\end{array} \\ & \text { Fourier-transform infrared spectroscopy } \\ \text { GTA } & \text { Glutaraldehyde } \\ \text { DHT } & \text { De-hydrothermal treatment } \\ \text { IR } & \text { Irradiation } \\ \text { TIPS } & \text { Thermally induced phase separation } \\ \text { kGy } & \text { Kilo gray } \\ \text { DT } & \text { Denaturation temperature } \\ \text { HEMA } & \text { 2-Hydroxyethyl Methacrylate } \\ \text { Co60 } \gamma & \text { Cobalt sixty gamma } \\ \text { LDT } & \text { Liquid displacement technique } \\ \text { TGA } & \text { Thermal gravimetric analyzer } \\ \text { PBS } & \text { Phosphate buffer saline } \\ \text { TFA } & \text { Trifluoroacetic acid } \\ \text { n- } \beta \text {-TCP } & \text { Nano- } \beta \text {-tricalcium phosphate/collagen } \\ \text { DW } & \text { Distilled water } \\ \text { RT } & \text { Room temperature } \\ \text { PSC } & \text { Pepsin soluble collagen } \\ \text { ASC } & \text { Acid soluble collagen } \\ \text { PLGA } & \text { Poly lactic-co-glycolic acid } \\ \text { AF-MSCs } & \text { Amniotic fluid-derived mesenchymal stem } \\ & \text { cells } \\ \text { ARS } & \text { Alizarin red staining } \\ & \end{array}$

\section{Introduction}

Bone fractures remain a challenge in reconstructive and rehabilitation surgery. For instance, periodontal bone defects are very common in developing world and require a large amount of medical resources (Wang et al. 2016; Gaihre et al. 2017). Currently, implantable biomaterials such as demineralized bone granules, auto- and allografts are available and clinically used. However, these approaches involve several drawbacks such as post-operative pain, increased blood loss, and secondary surgical wounds (Kumar et al. 2016; Oryan et al. 2014). Allografting could overcome these limitations, but it is associated with the risk of infectious diseases, an insufficient number of donors and high costs (Greenwald et al. 2012). Recombinant growth factors, cellbased engineered bone substitutes and commercial scaffolds are sophisticated alternatives which are widely accepted in the developed world but are too expensive for patients in the low-income countries (Mao and Mooney 2015; Tollemar et al. 2016; Tong et al. 2016a, b). Recently, the interest in the development of scaffolds from naturally available and lowcost bioactive materials has increased significantly (Baino et al. 2015; Yi et al. 2016). These materials could improve bone function by providing a suitable microenvironment for tissue growth and regeneration (Yu et al. 2013; PoloCorrales et al. 2014; Maisani et al. 2017).

Since hydroxyapatite (Ha) and collagen type 1 (Col1) are the major constituents of human bone, they are widely studied as promising materials for scaffold preparation. For example, the usefulness of porous nano-Ha/Col scaffolds for restoration of critical-size bone defect was reported (Wang et al. 2017). Beside commercial available synthetic Ha, many laboratories have extracted $\mathrm{Ha}$ from bio-waste such as bovine bones (Wua et al. 2016; Kim et al. 2014; Sofronia et al. 2014). Bioactive molecules such as Col1 and chitosan (Cs) are also used as components for bone composite engineering (Wang et al. 2016; Croisier and Jérôme 2013; Maji et al. 2016; Tong et al. 2016a, b) which can be extracted from animal skins (Kukhareva et al. 2010; Pacak et al. 2014) and brine shrimp, respectively (Khan et al. 2005; Maji et al. 2016). For instance, human mandible bone defects were restored by grafting of Coll in combination with dental pulp progenitor cells (d'Aquino et al. 2009; Chamieh et al. 2016). Cs has reactive amine and hydroxyl groups which promote osteoblast growth and in vivo bone formation (Levengood and Zhang 2014) and has structural similarities with glycosaminoglycans, a major component of bone and cartilage (Nagahama et al. 2009; Gravel et al. 2006). In an advanced study, Cs and Cs-hydrogel were used as a bio-printable ink for bone tissue engineering (Demirtaş et al. 2017).

$\mathrm{Ha}, \mathrm{Col1}$ and Cs were described to have desired properties such as tissue compatibility, antibacterial activity, non-toxicity, non-immunogenicity, non-carcinogenicity and solubility (Pallela et al. 2012). These components can form a direct chemical bond with living cells/tissues and promote tissue growth, which makes them interesting for the use in orthopedic and dental applications (Rodríguez-Vázquez et al. 2015; Echazú et al. 2016). For example, the applicability of collagen-hydroxyapatite scaffolds for restoration of the mandible in the rabbit has been demonstrated (Zhang et al. 2013). Additionally, human adipose-derived MSCs seeded into a Col-Ha scaffold-promoted ectopic bone formation after implantation in the mouse (Calabrese et al. 2017). Cs in combination with silk-fibroin was observed to be biocompatible with osteogenic potentials when transplanted in a rabbit mandible defects model, including TGF- $\beta 1$ supplementation (Tong et al. 2016a, b).

$\mathrm{Ha}, \mathrm{Col1}$ and Cs are usually animal originated and easy to obtain. So far, composites out of $\mathrm{Ha}$, Cs and Coll for non-load-bearing mandible bone restoration have not been widely studied. We fabricated $\mathrm{Ha} \cdot \mathrm{Col1} \cdot \mathrm{Cs}$ scaffolds from in-house rabbit skin (Col1), bovine bones (Ha) and prawn shell (Cs) and modified them using different cross-linking methods. The resulting scaffolds were characterized for cytotoxicity, biodegradability, in vivo biocompatibility and physical, chemical, and morphological properties. 


\section{Materials and methods}

\section{Fabrication procedures of Ha.Col1.Cs scaffolds}

The in-house extraction methods of $\mathrm{Ha}, \mathrm{Coll}$ and $\mathrm{Cs}$ from naturally available sources have been described in Supplementary Materials and Methods. Scaffolds were fabricated according to a previous described thermally induced phase separation method with some modifications (Chen et al. 2010). In brief, $3 \mathrm{~g}$ Ha was weighed into a flask and deionized water was added. The mixture was stirred at room temperature (RT) for $5 \mathrm{~h}$ and was ultrasonicated until the Ha powder was thoroughly dispersed. At the same time, $70 \mathrm{~mL}$ of collagen solution $(5 \mathrm{mg} /$ $\mathrm{mL}$ ) was transferred into another flask and stirred at RT. Then, $1.67 \mathrm{~g}$ of chitosan was added slowly to the collagen solution and stirred at RT to form a chitosan-collagen mixture. After that, the Ha solution was added to the collagen-chitosan mixture and stirred for $2 \mathrm{~h}$ to disperse thoroughly. Afterwards, the mixture was transferred to a mold and pre-frozen at $-40{ }^{\circ} \mathrm{C}$ for $24 \mathrm{~h}$, followed by freeze-drying at $-55^{\circ} \mathrm{C}$ using a constant cooling freezedrying protocol.

The resulting freeze-dried scaffold was modified using four different methods: chemical cross-linking with (1) HEMA and (2) GTA solution and physical crosslinking by (3) DHT and (4) IR. Cross-linkings were accomplished by immersing the freeze-dried scaffold in a cross-linker solution containing 2.5\% HEMA or 2.5\% GTA solution, respectively, for $4 \mathrm{~h}$ at RT. The scaffolds were washed with deionized water for $1 \mathrm{~h}$. After that, scaffolds were frozen and lyophilized as described above. For the DHT method, lyophilized scaffolds were put under a vacuum at a temperature of $110{ }^{\circ} \mathrm{C}$ for $24 \mathrm{~h}$. For IR, fabricated scaffolds were irradiated at 5-30 kGy using Co60 $\gamma$ sources. The resulting scaffolds were named according to the methods used for modification: Ha.Coll-Cs-GTA, Ha.Coll.CsIR, Ha.Col1·Cs-DTH and Ha.Col1·Cs-HEMA.

\section{X-ray diffraction (XRD) analysis}

The phase and crystallinity of Ha nano-powder were evaluated using XRD (X'Pert PRO PW 3040, PANalytical, Netherlands). The parameter was $\mathrm{CuK} \alpha$ radiation with a wavelength of $1.78896 \AA$ and over a range of $2 \theta$ from $10^{\circ}$ to $70^{\circ}$ angle, step size $0.02 / \mathrm{s}$ with $40 \mathrm{kV}$ voltages and $30 \mathrm{~mA}$ current. The XRD pattern was analyzed and compared with "X"pert high score and "X'Pert plus" software ["Xpert Highscore" File No. 01-086-0740 (ICDD 2005)] to identify the phase (Degen et al. 2014; Markvardsen et al. 2008).

\section{Fourier-transform infrared spectroscopy (FTIR) analysis}

The stretching frequencies of Ha were examined by FTIR analysis (FTIR 8400S, Shimadzu spectrophotometer, Japan) in the range of $4000-400 \mathrm{~cm}^{-1}$. For Col1, samples were directly placed in the sample holder (IRprestige21, Shimadzu, Japan). FTIR spectra were recorded with FTIR 8400S Shimadzu Spectrophotometer in the range of $4000-700 \mathrm{~cm}^{-1}$, at a resolution $4 \mathrm{~cm}^{-1}$, number of scan: 20 times. For identifying organic, polymeric and inorganic materials within the four distinct Ha.Col1.Cs scaffolds, infrared light was used.

\section{Scanning electron microscopy (SEM) imaging}

The morphology of Ha crystals as well as the pore structure morphology of the Ha.Coll.Cs scaffolds was obtained by SEM (JSM 6490LA, Jeol, Japan). The surface of the scaffolds was platinum coated to make it conductive and then the samples were placed inside the SEM chamber.

\section{Determination of porosity and density of $\mathrm{Ha} \cdot \mathrm{Col} 1 \cdot \mathrm{Cs}$ scaffold}

The density and porosity of the fabricated scaffolds were measured by liquid displacement test (LDT) using ethanol as the liquid. A sample with a known weight $(W)$ was immersed in a graduated cylinder in a known volume of ethanol $\left(V_{1}\right)$ for $5 \mathrm{~min}$. The total volume of ethanol in the cylinder and ethanol impregnated scaffold was $V_{2}$. The ethanol impregnated scaffold was removed from the cylinder and the residual ethanol volume was recorded $\left(V_{3}\right)$. For each scaffold, five independent measurements were done $(n=5)$. The density $(d)$ and the porosity $(G)$ of the scaffolds are calculated using these formulas:

$d=W /\left(V_{2}-V_{3}\right)$,

$\varepsilon=\left(V_{1}-V_{3}\right) /\left(V_{2}-V_{3}\right)$.

\section{Determination of swelling ability of Ha.Col1.Cs scaffold}

The swelling ability was determined by the percentage of water absorption. Dry weight of the scaffold was denoted as $\mathrm{Wd}$.

In brief, the scaffolds were immersed in PBS buffer solution with $\mathrm{pH} 7.4$ at $37^{\circ} \mathrm{C}$ for 2, 24, 48 and $72 \mathrm{~h}$. Afterward, the scaffolds were taken out and their wet weight $\left(W_{\mathrm{w} 1}\right)$ was 
measured. In this case, we assessed the swelling ability of the scaffold structure employing its porous structure. In the second measurement, the same swollen samples were pressed between filter paper to remove the fluid remaining in the pores and then weighed $\left(W_{\mathrm{w} 2}\right)$. In this way, the intrinsic water absorbance ability of the scaffold material was assessed. For each scaffold, five independent measurements were done $(n=5)$. The swelling ratio of the scaffold was defined as the ratio of the weight increase $\left(W_{\mathrm{w}}-W_{\mathrm{d}}\right)$ to the initial weight $\left(W_{\mathrm{d}}\right)$ according to following equation:

Swelling ability $(\%)=\left(W_{\mathrm{W}}-W_{\mathrm{d}}\right) / W_{\mathrm{d}} \times 100$,

where $W_{\mathrm{W}}$ represents $W_{\mathrm{w} 1}$ or $W_{\mathrm{w} 2}$

\section{Stability test for Ha.Col1.Cs scaffolds}

Dried scaffolds were immersed into two different aqueous solutions ( $\mathrm{pH} 4$ and 7) at RT for intervals from 1 day up to 5 days. Scaffolds were then removed and dried for $48 \mathrm{~h}$ in a vacuum oven at $50{ }^{\circ} \mathrm{C}$. A second weighing was conducted to determine the stabilities of the scaffolds by determining their weight loss. The stability of the scaffolds in the aqueous solution was calculated with the following equation:

$S=\left(W_{2} / W_{1}\right) \times 100$,

where $S$ is the percentage of the weights of the scaffolds remaining after the test, $W_{1}$ and $W_{2}$ are, respectively, the weights of dried scaffolds before and after the test.

\section{Assessment of mechanical strength}

Samples with a diameter of $15 \mathrm{~mm}$ and a height of $14 \mathrm{~mm}$ were prepared for mechanical strength testing. The test was carried out using a mechanical testing machine (Z.05, Zwick/ Roell, Germany) at RT. The cross-head speed was set at $2 \mathrm{~mm} /$ $\mathrm{min}$. The compressive modulus was calculated from the slope of the stress-strain curve in the linear region (strain from 2 to $5 \%$ ). Each measurement was repeated five times and the average value was calculated.

\section{Biodegradability study of Ha.Col1.Cs scaffolds}

To study the biodegradability, scaffolds were immersed in PBS-containing lysozyme $(10,000 \mathrm{U} / \mathrm{ml})$ at $37{ }^{\circ} \mathrm{C}$ for up to 21 days. At specific time points, the scaffolds were washed in deionized water to remove ions absorbed on the surface. Consecutively, the samples were lyophilized.

The degradation of the scaffold was calculated using following equation:

Biodegradability $(\%)=\frac{W_{\mathrm{o}}-W_{\mathrm{t}}}{W_{\mathrm{o}}} \times 100$, where $W_{0}$ is the initial and $W_{\mathrm{t}}$ is the dry weight of the scaffold.

\section{In vitro cytotoxicity and biocompatibility assay for $\mathrm{Ha}$, Col1, Cs and Ha.Col1.Cs scaffolds}

Cytotoxicity tests of the extracted Col1, Ha, Cs and scaffolds on brine shrimp (Artemia salina) were performed as described (Khan et al. 2012).

For in vitro blood biocompatibility assay, heparinized human blood was used. Ha, Coll and Cs and Ha.Col1.Cs scaffolds powder were diluted with different ratios of blood. Blood sample diluted at the same ratios with deionized water and PBS served as controls. These mixtures were spread on glass slides after $2 \mathrm{~h}$ incubation at RT and observed under a light microscope.

\section{In vitro cell culture, attachment and growth in the presence of scaffold}

Amniotic fluid-derived mesenchymal stem cells (AF-MSCs) were isolated and cultured in Chang $\mathrm{C}$ media containing 88\% $\alpha$ MEM (Minimum Essential Medium Eagle Alpha Modification; Sigma) with 10\% FBS, 1\% GlutaMAX, $1 \%$ penicillin/streptomycin (all Gibco), 10\% Chang B Basal Medium, and 2\% Chang C supplement (Irvine Scientific) as described earlier (Spitzhorn et al. 2017). For observing the attachment, compatibility and growth of AF-MSCs in the presence of the Ha.Col1.Cs scaffolds, equal numbers of cells were seeded in 12-well plates with equal amounts scaffold nano-powder. Wells without any scaffold powder served as negative controls. Light microscopy images of the cells were taken on days 2, 5 and 10.

\section{In vitro degradability and mineralization study}

To test the degradability of the scaffolds by AF-MSCs, we continued the cell attachment and growth assay for 21 days and the size-reduction of scaffold nano-powder particles was observed microscopically. After 21 days, upon degradation of the nano-powder, mineralized nodules were formed at the site of clustered AF-MSCs which were confirmed using alizarin red staining. The respective wells were washed three times with PBS and stained as described previously (Rahman et al. 2018).

\section{Histological and radiological analysis of in vivo grafted Ha.Col1.Cs scaffolds}

The experimental model used in this study was a surgically created mandible critical-sized defect in rabbits (Oryctolagus cuniculus). Prior to the study, ethical approval was obtained from the institutional animal ethics committee of atomic 
energy research establishment. The surgery protocol was conducted in accordance with the regulations on animal welfare and complied with the guidelines.

During the experimental period, the rabbits were held in cages with pelleted food, hay and water at RT in a humidity controlled room. All animals were subjected to $12 \mathrm{~h}$ day/night cycles. Importantly, the animals were acclimatized for 15 days prior to surgery. Total 16 adult male rabbits $(1.5-2.0 \mathrm{~kg})$ were recruited for the study and assigned in 4 groups: mandibular defects were implanted with (1) Ha.Coll·Cs-IR, (2) Ha.Col1.Cs-DHT, and (3) human bone graft/chips as a positive control, or (4) empty defect as a negative control. Under aseptic conditions, the rabbits were first intravenously anesthetized with $2 \%$ pentobarbital sodium $(30 \mathrm{mg} / \mathrm{kg})$. The hair on the site of the mandible was then trimmed. Then a $20 \mathrm{~mm}$ longitudinal skin incision was made and subcutaneous tissues were separated gently along the upper edge of the rabbit mandible. An appropriate defect size of $15 \mathrm{~mm}$ height $\times 3 \mathrm{~mm}$ width $\times 2 \mathrm{~mm}$ depth was made, using an orthopedic hand drill machine with a drill bit size of $1.5 \mathrm{~mm}$, under saline irrigation to avoid thermal necrosis. To make the scaffolds compliant and resilient, the scaffolds were soaked in blood that oozed out from the incision during surgery. The scaffold constructs were then implanted into the defect. Subsequently, the skin incision was then sutured with nylon, using horizontal mattress sutures. The surgical wound was cleaned with povidone iodine (5\%) and dressed with nitro-furazone ointment. Animals were housed in individual pens for 7 days post-surgery to restrict activity during the initial stages of healing and then transferred to group pens for the remainder of the study. Analgesia and antibiotics were administered after surgery. Inj. Ceftriaxone $250 \mathrm{mg}$ (TRIZON VET, ACME Laboratories Ltd, Bangladesh) was administered twice for 7 days Intra-muscular (I/M) and Inj. ketoprofen (K-Pain Vet, ACI Limited, Bangladesh) $0.5 \mathrm{~mL}$ was administered once daily (I/M). Sutures were removed on day 8 . After 4 months, the experimental animals were killed, the skin was excised and the mandible bone samples of the scaffold-treated site were surgically collected for histological examinations. Excised bone fragments were fixed, dehydrated, and embedded in paraffin and cut into $5 \mathrm{~mm}$ sections with a microtome. Tissue sections were subjected to hematoxylin and eosin (H\&E) staining and were viewed with a light microscope (Olympus BX51, Japan). X-ray radiological images were taken to observe in vivo bone formation at several time points during the progression of recovery.

\section{Results}

\section{Fabrication of Ha.Col1.Cs scaffolds from hydroxyapatite, collagen, and chitosan}

The manufacturing process of $\mathrm{Ha} \cdot \mathrm{Col1} \cdot \mathrm{Cs}$ scaffold as described in the method section led to a stable co-precipitated Ha.Col1.Cs composite consisting of $\mathrm{Ha}, \mathrm{Coll}$ and Cs. To optimize the molecular links between the constituents, the composite material was chemically and physically cross-linked. Four types of scaffolds Ha.Col1.Cs-IR, $\mathrm{Ha} \cdot \mathrm{Col1} \cdot \mathrm{Cs}-\mathrm{GTA}$, Ha.Col1.Cs-DHT, and Ha.Col1.CsHEMA were prepared using physical cross-linkers DHT and IR; and chemical method cross-linking with HEMA and GTA solution (Fig. 1). The characterization of inhouse-extracted hydroxyapatite and collagen type 1 has been provided in supplementary results (Figures S1, S2).

\section{Fourier-transform infrared spectroscopy (FTIR) analysis of the scaffolds}

FTIR analysis revealed the usefulness of chemical and physical cross-linker in the scaffold to form better network (Fig. 2). The FTIR spectra of native Ha clearly exhibit peaks at 602,962 , and $1035 \mathrm{~cm}^{-1}$, corresponding to $\mathrm{PO}_{4}^{-3}$ ion. A small and sharp band was detected at $3572 \mathrm{~cm}^{-1}$, corresponding to the stretching mode of the $-\mathrm{OH}$ group, which results from hydrated calcium phosphate such as Ha. A weak peak was observed at $876 \mathrm{~cm}^{-1}$ and strong peak at $1450 \mathrm{~cm}^{-1}$ which correspond to the stretching vibration of $\mathrm{CO}_{3}{ }^{2-}$ ions confirming that $\mathrm{Ha}$ crystals containing $\mathrm{CO}_{3}{ }^{2-}$. The characteristic bands for $\mathrm{HPO}_{4}{ }^{2-}$ were shown at $1133 \mathrm{~cm}^{-1}, 1064 \mathrm{~cm}^{-1}, 989 \mathrm{~cm}^{-1}, 577 \mathrm{~cm}^{-1}$ and $527 \mathrm{~cm}^{-1}$. Similarly, the broad bands at about 3200 and $2800 \mathrm{~cm}^{-1}$ corresponded to the absorbed hydrate ion and short peaks in the range $3570-3670 \mathrm{~cm}^{-1}$ belong to the stretching vibrations of lattice $\mathrm{OH}-$ ions of hydroxyapatite (Fig. 2a).

For chitosan, the spectrum around $3430 \mathrm{~cm}^{-1}$ attributed to the pooled stretching vibration of $\mathrm{OH}$ and $\mathrm{N}-\mathrm{H}$ groups. The band at $2845 \mathrm{~cm}^{-1}$ corresponded to the $\mathrm{CH}$ bond stretching. The comprehensive bands at 1637 and $1543 \mathrm{~cm}^{-1}$ were assigned to the existence of amide I and amide II groups. The sharp band at $1408 \mathrm{~cm}^{-1}$ was attributed to the stretching of carbonyl from the $\mathrm{COO}^{-}$group. The low intense bands at 1382 and $1321 \mathrm{~cm}^{-1}$ were attributed to the $\mathrm{CH}$ bending vibrations of the ring. The featured peaks of $\mathrm{C}-\mathrm{O}-\mathrm{C}$ glycosidic linkage were shown at the region of $1153-1021 \mathrm{~cm}^{-1}$ (Fig. 2a). FTIR of collagen type 1 detected bands of amide A $\left(3299 \mathrm{~cm}^{-1}\right)$, amide B $\left(2950-2919 \mathrm{~cm}^{-1}\right)$, amide I $\left(1632-1664 \mathrm{~cm}^{-1}\right)$, amide II $\left(1500-1585 \mathrm{~cm}^{-1}\right)$ and amide III (1200-1300 $\left.\mathrm{cm}^{-1}\right)$ (Fig. 2a). 


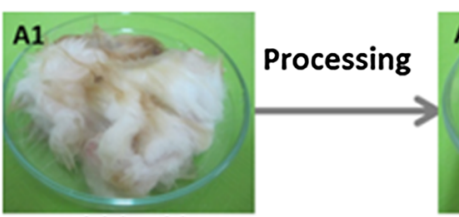

Rabbit Skin

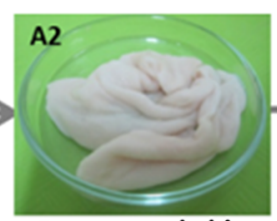

Pretreated skin
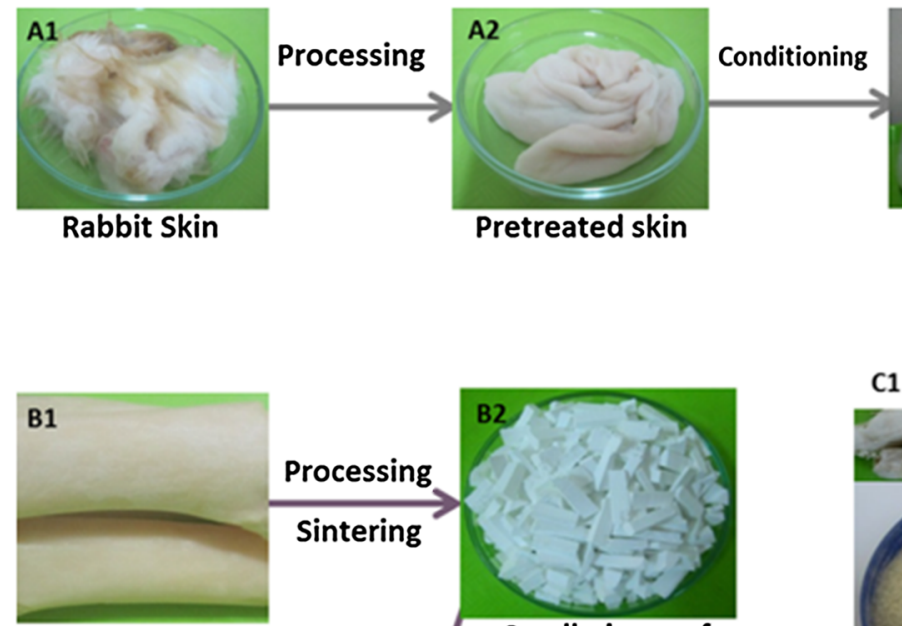

Bovine bone

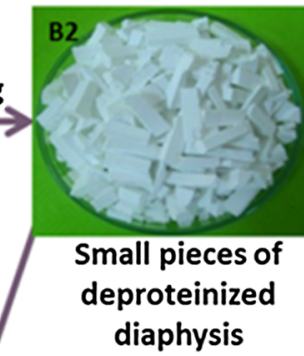

Conditioned
small pieces

of skin

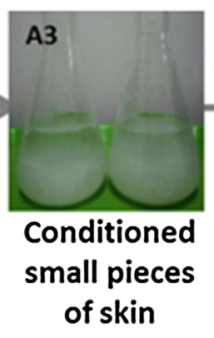

C1

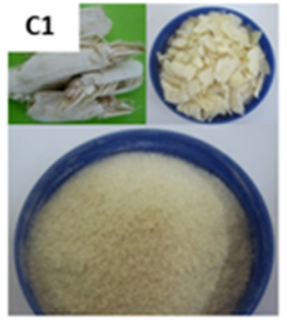

Chitosan

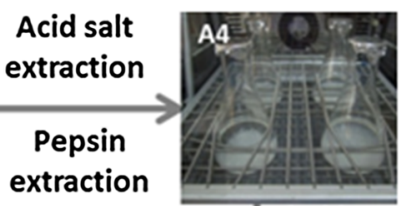

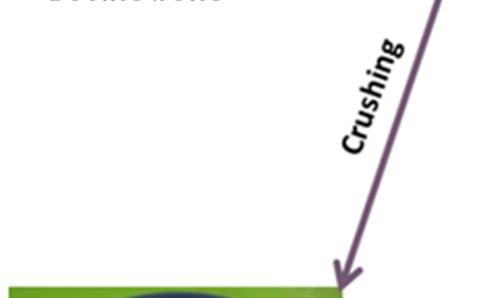

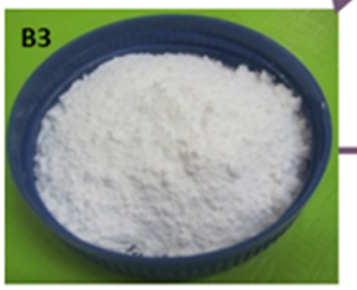

Ha powder

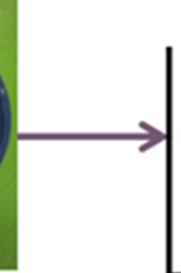

Hydroxyapatite

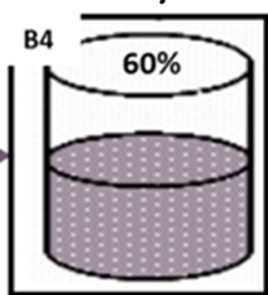

Collagen-Chitosan slurry

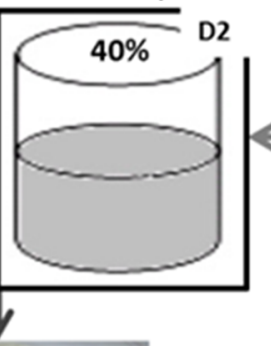

D2

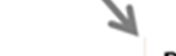

D1
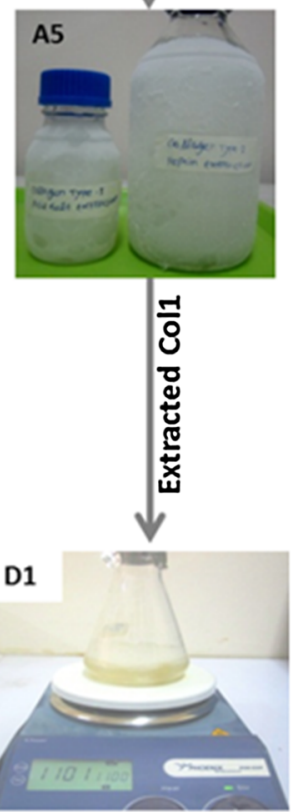

Chitosan: Collagen 1 2:1

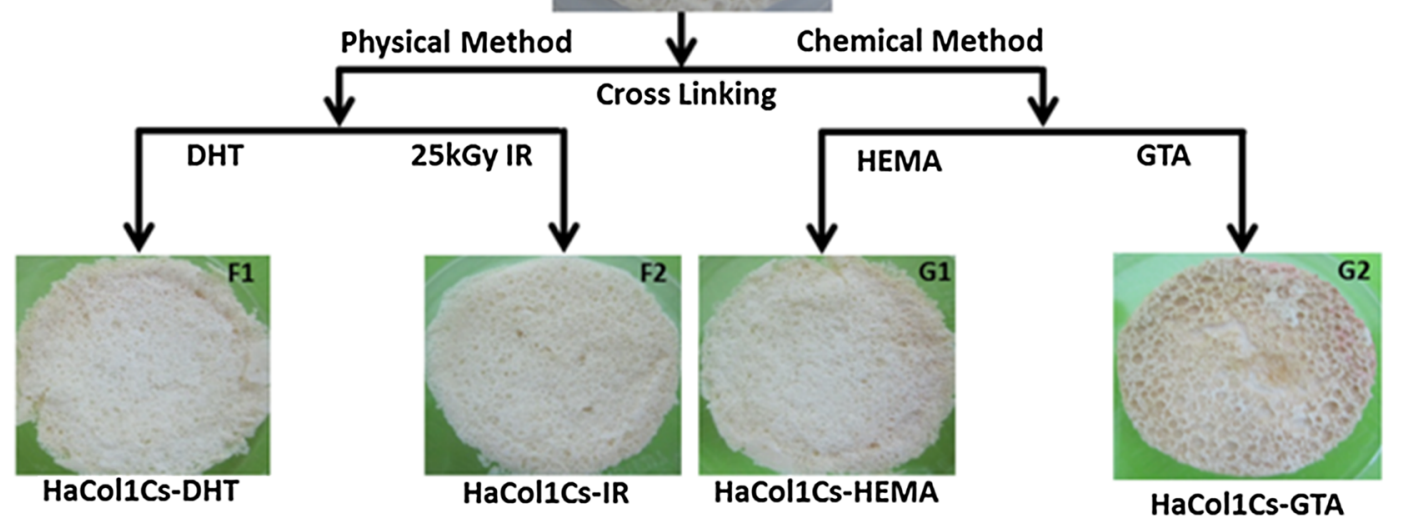

Fig. 1 Schematic representation for the fabrication of porous Ha.Col1.Cs scaffold. (A1-A5) Isolation steps of Col1. (B1-B3) Extraction and processing of Ha. (B4) Dispersion of HA powders in the water. (C1) Extracted brine shrimp derived Cs. (D1) Mixing of $\mathrm{Cs}$ in the Col1 solution at 2:1 ratio. (B4 and D2) Mixture of Ha slurry, and Cs-Col1 solution at 60:40 ratio and homogenization. (E) Freeze-dried Ha.Col1.Cs scaffold without cross-linkers. Cross-linked fabricated scaffold with physical method (DHT and IR) (F1-F2) and chemical method (HEMA and GTA) (G1-G2) 

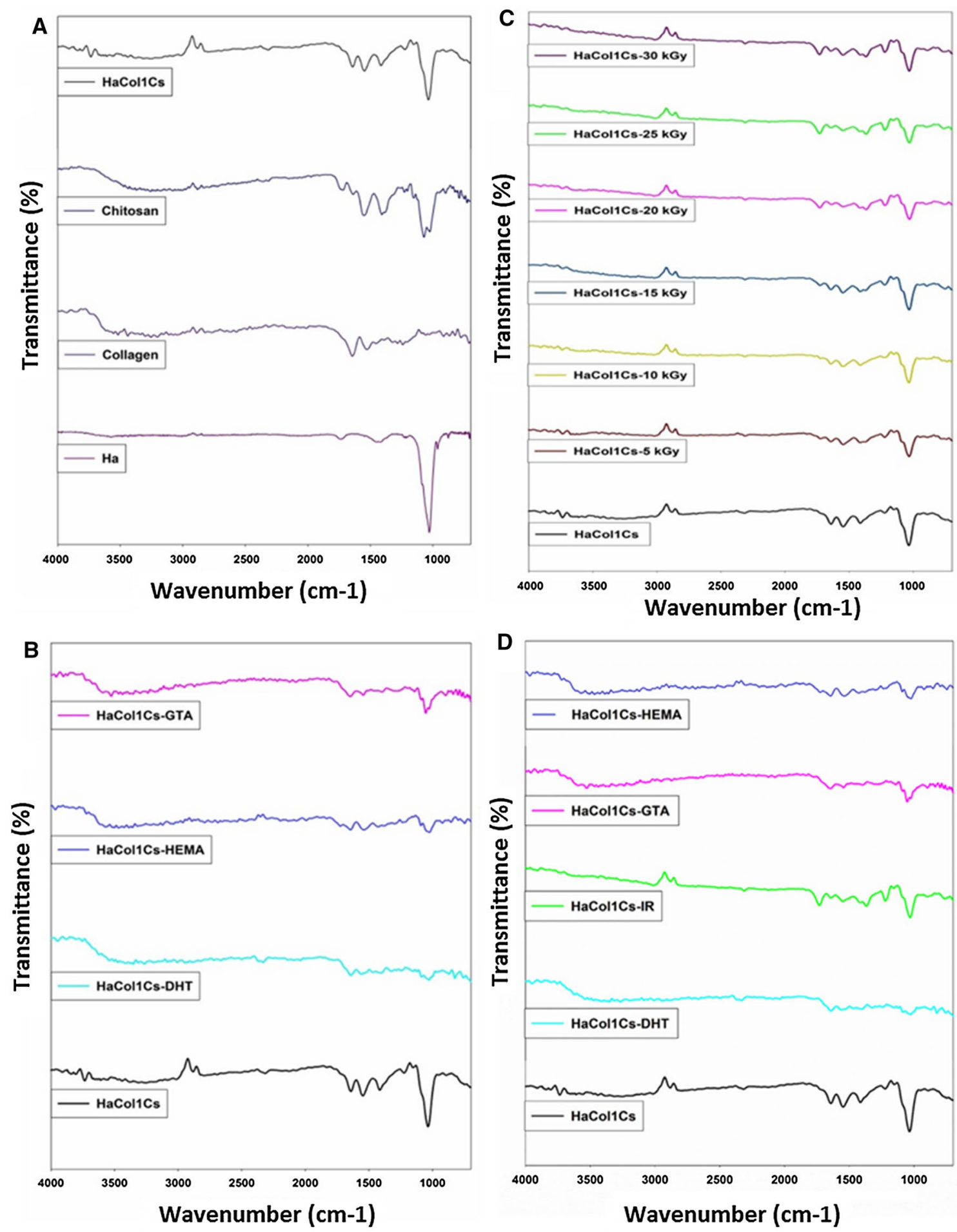

Fig. 2 FTIR spectra of Ha.Col1.Cs scaffolds with and without cross linkers. a Ha.Coll.Cs (without cross-linkers) spectra with corresponding individual constituents namely $\mathrm{Ha}$, Cs and Col1. b FTIR analysis for Ha.Col1.Cs-DHT, Ha.Coll-Cs-HEMA, and Ha.Coll·CsGTA where $\mathrm{Ha} \cdot \mathrm{Coll} \cdot \mathrm{Cs}$ (without cross-linkers) served as reference. c

Effects of various radiation doses on $\mathrm{Ha} \cdot \mathrm{Coll}$.Cs scaffold as a crosslinker. d Comparative analysis of FTIR spectra between Ha.Col1.Cs (without cross-linkers), Ha.Coll·Cs-DHT, Ha.Coll·Cs-IR (25 kGy), Ha.Coll-Cs-HEMA and Ha.Coll-Cs-GTA 
The main absorption bands of $\mathrm{Ha} \cdot \mathrm{Coll} \cdot \mathrm{Cs}$ scaffolds (without cross-links) are amide A $\left(3299 \mathrm{~cm}^{-1}\right)$, amide B (2950-2919 $\left.\mathrm{cm}^{-1}\right)$ and amide I (1632-1664 $\left.\mathrm{cm}^{-1}\right)$ with $\mathrm{N}-\mathrm{H}$ stretching signature. Amide II (1500-1585 $\left.\mathrm{cm}^{-1}\right)$ and amide III (1200-1300 $\left.\mathrm{cm}^{-1}\right)$ were also detected in the composite. A free $\mathrm{N}-\mathrm{H}$ stretching vibration is present between 3400 and $3440 \mathrm{~cm}^{-1}$. When the $\mathrm{NH}$ group of a peptide is evolved in a hydrogen bond, this position is moved to around $3300 \mathrm{~cm}^{-1}$. The characteristic bands for $\mathrm{OH}-$ appeared at $3452-3782 \mathrm{~cm}^{-1}$. Other functional groups such as amide III, $\mathrm{PO}_{4}{ }^{3-} V_{3}$, and asymmetric $\mathrm{HPO}_{4}{ }^{2-}$ were detected (Fig. 2a).

In this study, carbonate $V_{2}$ was identified in sample $\mathrm{Ha} \cdot \mathrm{Col1} \cdot \mathrm{Cs}-\mathrm{DHT}$, Ha.Col1.Cs-IR and Ha.Col1.Cs-GTA at $824-870 \mathrm{~cm}^{-1}, 898 \mathrm{~cm}^{-1}$ and $897 \mathrm{~cm}^{-1}$ sequentially. $\mathrm{CO}_{3} V_{3}$ was detected in the samples $\mathrm{Ha} \cdot \mathrm{Col} \cdot \mathrm{Cs}\left(1412,1543 \mathrm{~cm}^{-1}\right)$, Ha.Col1.Cs-DHT $\left(1402,1560 \mathrm{~cm}^{-1}\right)$, Ha.Coll $\cdot$ Cs-IR (1415, $\left.1549 \mathrm{~cm}^{-1}\right)$ and Ha.Col1.Cs-GTA $\left(1397,1545 \mathrm{~cm}^{-1}\right)$. Amide I was found for samples Ha.Col1.Cs, Ha.Col1.Cs-DHT, $\mathrm{Ha} \cdot \mathrm{Col1} \cdot \mathrm{Cs}-\mathrm{IR}$ and Ha.Col1.Cs-GTA at 1639, $1643 \mathrm{~cm}^{-1}$; 1641 and $1645 \mathrm{~cm}^{-1}$ correspondingly. The $\mathrm{N}-\mathrm{H}$ stretching was also shown for sample Ha.Col1·Cs, Ha.Col1·Cs-DHT, $\mathrm{Ha} \cdot \mathrm{Col1} \cdot \mathrm{Cs}-\mathrm{IR}$ and $\mathrm{Ha} \cdot \mathrm{Col1} \cdot \mathrm{Cs}-\mathrm{GTA}$ at $3213,3398 \mathrm{~cm}^{-1}$; $3266 \mathrm{~cm}^{-1} ; 3123,3572 \mathrm{~cm}^{-1}$; and $3185,3526 \mathrm{~cm}^{-1}$, respectively. Besides this, other functional groups such as amide III, $\mathrm{PO}_{4} V_{3}$ and asymmetric $\mathrm{HPO}_{4}{ }^{2-}$ were found (Fig. 2b).

In case of various irradiated samples (Fig. 2c), FTIR spectra showed a band of amide I stretching at $\sim 1635 \mathrm{~cm}^{-1}$ for Ha.Col1.Cs without cross-linking and for the irradiated scaffolds (5-20 kGy). However, a high radiation dose (25 and $30 \mathrm{kGy}$ ) shifted the band to $1643 \mathrm{~cm}^{-1}$. The amide II stretch at $1543 \mathrm{~cm}^{-1}$ was stable in all of the scaffolds, which indicated that radiation has no impact on amide II bond.

When HEMA was cross-linked to $\mathrm{Ha} \cdot \mathrm{Col1} \cdot \mathrm{Cs}, \mathrm{C}=\mathrm{O}$ stretching vibration was observed to shift from 1720 to $1608 \mathrm{~cm}^{-1}$ due to amide II of collagen. The interaction of the alkane group with the -OH group of HEMA shifted the $-\mathrm{OH}$ group. The $\mathrm{C}-\mathrm{O}$ stretching of HEMA was visible due to its shift from 1153 to $1091 \mathrm{~cm}^{-1}$ because of cross-linking with amide III of collagen (Fig. 2d).

\section{Morphology analysis of the scaffolds from scanning electron microscopy (SEM) image}

SEM images showed that all scaffolds exhibited irregular porous structures with moderate interconnections among the pores (Fig. 3). The wall of the macro-pores was detected to contain micro-pores. The pore diameter was 111.8-212.6 $\mu \mathrm{m}$ (mean 156.77 $\mu \mathrm{m} \pm 37$ ) for the Ha.Coll $\cdot \mathrm{Cs}$ composite (Fig. 3a). On the other hand, the pore diameter of $\mathrm{Ha} \cdot \mathrm{Col1} \cdot \mathrm{Cs}-\mathrm{IR}, \mathrm{Ha} \cdot \mathrm{Col1} \cdot \mathrm{Cs}-\mathrm{DHT}, \mathrm{Ha} \cdot \mathrm{Col1} \cdot \mathrm{Cs}-$ GTA and Ha.Col1.Cs-HEMA were 74.43-341.12 $\mu \mathrm{m}$ (mean 164.3 $\mu \mathrm{m} \pm 86$ ) (Fig. 3b), 87.86-125.68 $\mu \mathrm{m}$ (mean $101.69 \mu \mathrm{m} \pm 17$ ) (Fig. 3c), 212.6-376.09 $\mu \mathrm{m}$ (mean $273.43 \mu \mathrm{m} \pm 49$ ) (Fig. 3d) and 98-204 $\mu \mathrm{m}$ (mean $142 \mu \mathrm{m} \pm 40$ ) (Fig. 3e), respectively.

\section{Porosity, density, stability, mechanical strength and degradation study}

The porosity and density of the fabricated scaffolds were measured by liquid displacement test (LDT) using ethanol as a fluid. Ha.Col1.Cs-DHT, Ha.Col1.Cs-IR and $\mathrm{Ha} \cdot \mathrm{Col1} \cdot \mathrm{Cs}-\mathrm{GTA}$ scaffolds showed porosities of 94.24 , 95.29 and $90.64 \%$, in the order given. The highest porosity $(96.21 \%)$ was found in $\mathrm{Ha} \cdot \mathrm{Col1} \cdot \mathrm{Cs}$ without any crosslinker (Fig. 4a). Among the samples, the highest density was found for $\mathrm{Ha} \cdot \mathrm{Col1} \cdot \mathrm{Cs}-\mathrm{GTA}\left(0.38 \mathrm{~g} / \mathrm{cm}^{3}\right)$ and the lowest was found for $\mathrm{Ha} \cdot \mathrm{Col1} \cdot \mathrm{Cs}$ without any cross-linker $(0.28 \mathrm{~g} /$ $\mathrm{cm}^{3}$ ) (Fig. 4b). The highest swelling ratio was observed for the scaffold of without cross-linking $(\sim 306.24 \%)$ and the lowest was detected for Ha.Col1.Cs-GTA $(\sim 106.24 \%)$ after 72 h (Fig. 4c).

The biodegradation rate also varied between the different scaffolds. The lowest degradation rate was found in $\mathrm{Ha} \cdot \mathrm{Col1} \cdot \mathrm{Cs}-\mathrm{GTA}$ which was $10 \%$ (day 1) and $16 \%$ (day 21). On the other hand, scaffold without cross-linker (Ha.Col1.Cs) showed a faster degradation rate of 39\% (day 1) and 55\% (day 21) (Fig. 4d).

Mechanical strength test revealed that all cross-linked scaffolds had a higher mechanical strength than the initial Ha.Col1.Cs indicating that, mechanical properties of the scaffold were affected by cross-linking. Among the cross-linked scaffold, Ha.Col1.Cs-DHT showed the highest strength $\left(1.4 \mathrm{~N} / \mathrm{mm}^{2}\right)$ whereas $\mathrm{Ha} \cdot \mathrm{Col} 1 \cdot \mathrm{Cs}-\mathrm{GTA}$ and $\mathrm{Ha} \cdot \mathrm{Col1} \cdot \mathrm{Cs}-\mathrm{IR}$ had values around $1.2 \mathrm{~N} / \mathrm{mm}^{2}$ (Fig. $4 \mathrm{e}$ ).

Stability test of the fabricated scaffolds illustrated that scaffolds with cross-linker were more stable than Ha.Col.Cs without linker. In general, samples more stable were lower stable in neutral $\mathrm{pH}(\mathrm{pH} 7.0)$ than on mild acidic conditions ( $\mathrm{pH}$ 4.0). In both cases, Ha.Col1·Cs-GTA showed the highest stability (Fig. 4f).

\section{In vitro cytotoxicity and human blood biocompatibility analysis}

Brine shrimp lethality bioassay revealed that the composite biomaterials constituents ( $\mathrm{Ha}, \mathrm{Cs}$ and Col1) individually and the scaffold Ha.Col1.Cs as well as the physical cross-linked $\mathrm{Ha} \cdot \mathrm{Col1} \cdot \mathrm{Cs}-\mathrm{DHT}$, Ha.Col1·Cs-IR did not have a cytotoxic effect at a concentration of $<1 \mathrm{mg} / \mathrm{mL}$. However, chemical cross-linked scaffold Ha.Col1.Cs-HEMA and Ha.Col1.CsGTA were observed to be more lethal than others. In general, the mortality rate was increasing above $1 \mathrm{mg} / \mathrm{mL}$ concentration of the scaffolds (Fig. 5a). Biocompatibility was assessed by incubation of individual materials with human 

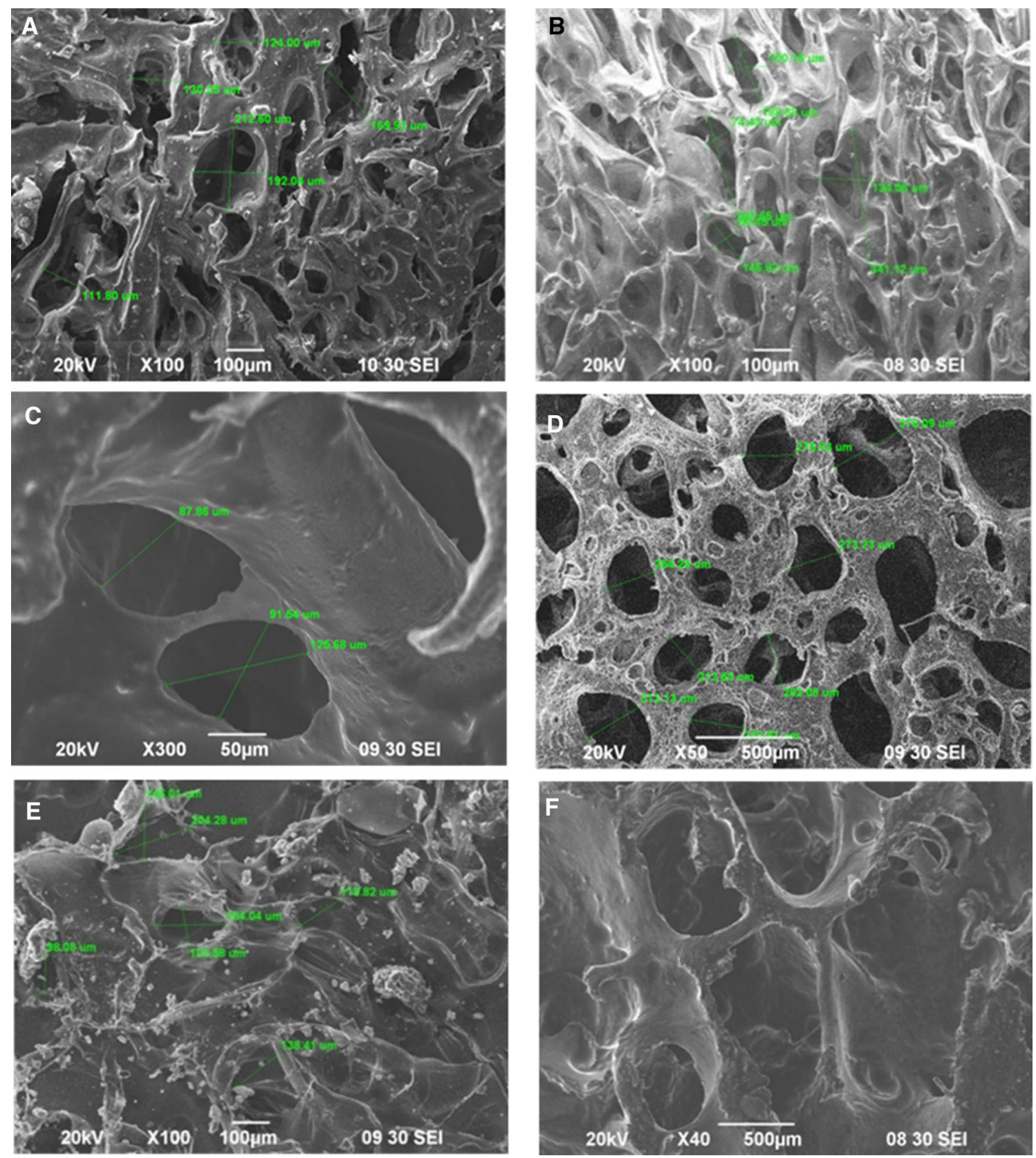

Fig. 3 SEM micrographs of different Ha.Coll.Cs scaffolds and human bone graft (HBG) from horizontal cross-sections at the middle region of the scaffold. a Ha.Coll.Cs scaffold without cross-linked. b Ha.Col1.Cs-IR scaffold cross-linked with $25 \mathrm{kGy}$ gamma irra-

red blood cells (RBCs) and showed no adverse effect on RBCs (Fig. 5b).

\section{AF-MSCs attachment, growth and mineralization observation}

We demonstrated human AF-MSCs attachment, viability and growth in the presence of the respective scaffolds diation. c Ha.Col1.Cs-DHT scaffold cross-linked with DHT method. d Ha.Col1.Cs-GTA scaffold cross-linked with GTA solution. e Ha.Col1.Cs-HEMA scaffold cross-linked with HEMA. f Human bone graft served as positive control

nano-powder (Fig. 6a). In the presence of Ha.Coll.Cs-IR and $\mathrm{Ha} \cdot \mathrm{Col1} \cdot \mathrm{Cs}-\mathrm{DHT}$, normal cell behavior was observed (Fig. 6A1, A4). In case of Ha.Col1.Cs-HEMA, a lower number of cells attached and the morphology of the cells was changed (Fig. 6A3, A8). However, Ha.Coll.Cs-GTA was observed to be lethal for AF-MSCs leaving almost no living cells after 2 days (Fig. 6A2). These results exhibit the compatibility of the Ha.Col1.Cs-IR and Ha.Col1.Cs-DHT 

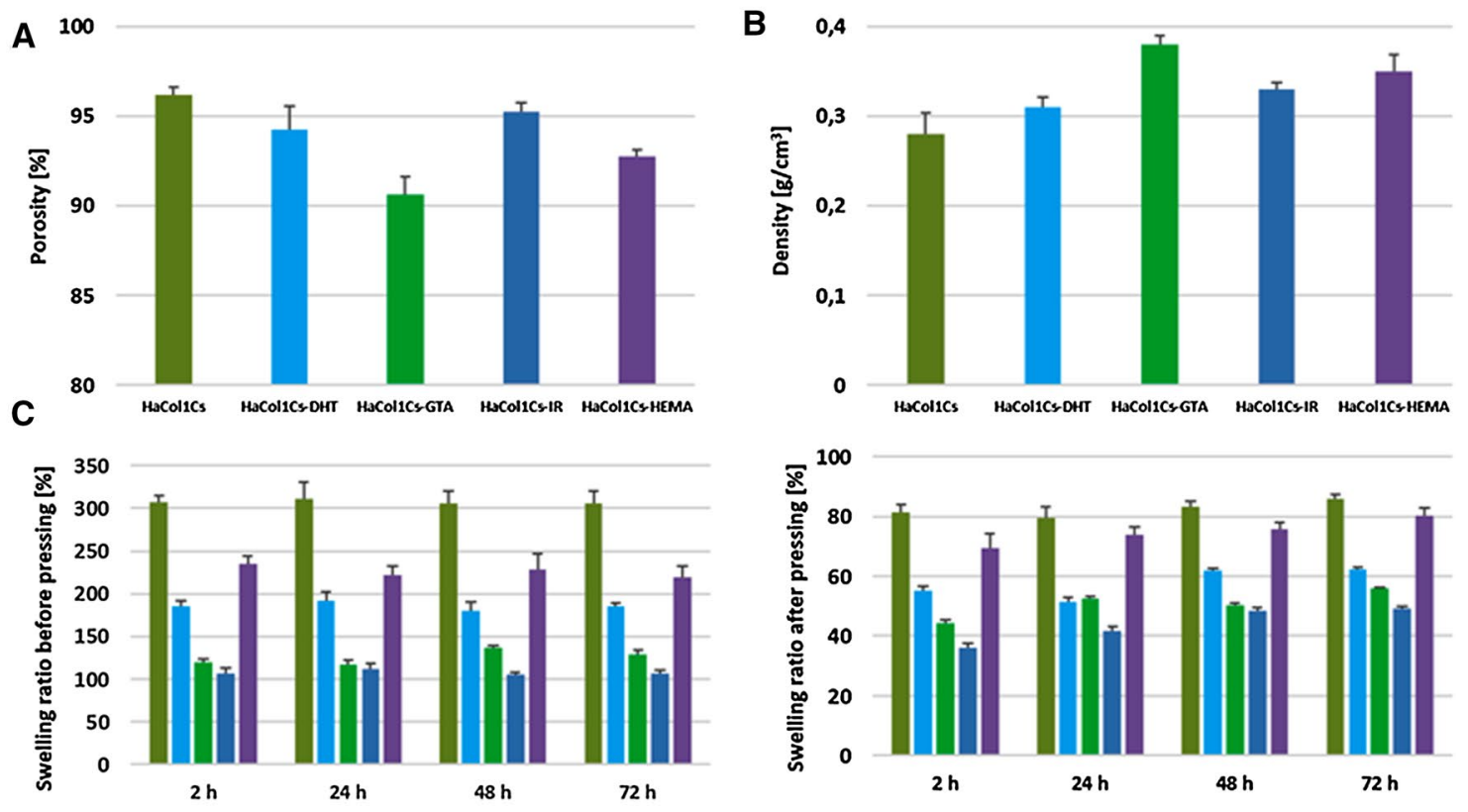

D $=$ HaCol1Cs $=$ HaCol1Cs-DHT $=$ HaCol1Cs-lR $\equiv$ HaCol1Cs-GTA $\equiv$ HaCol1Cs-HEMA

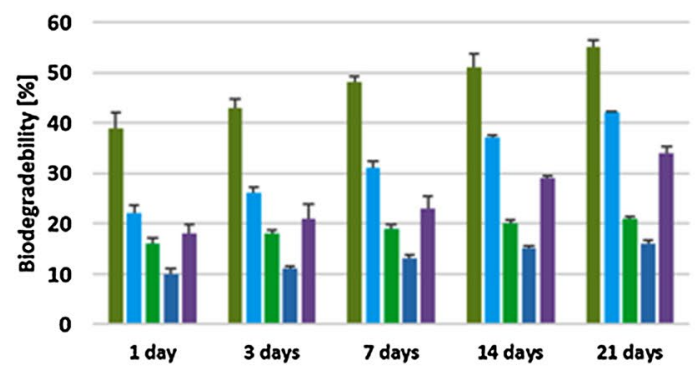

E
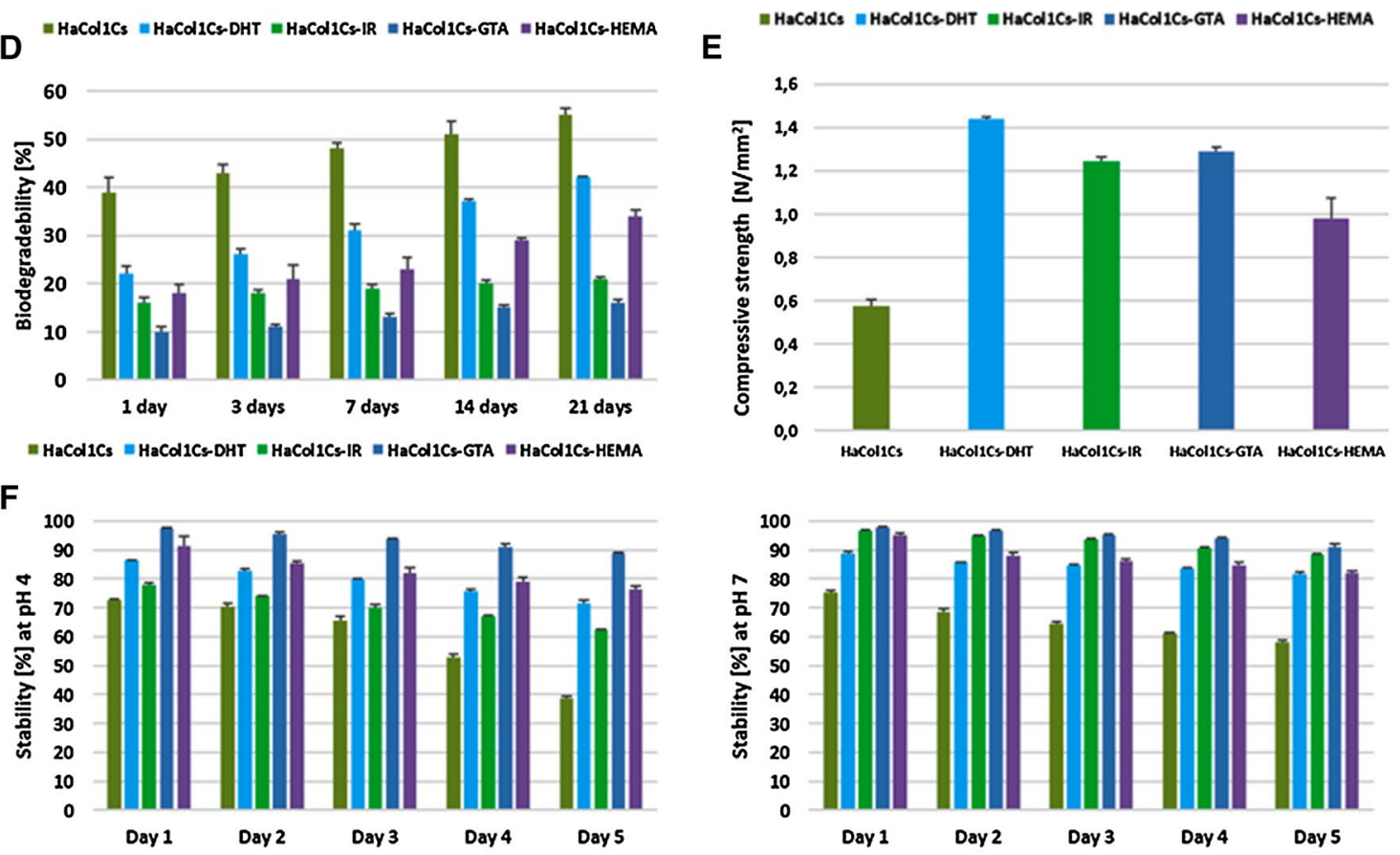

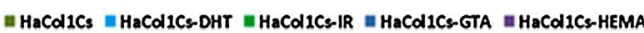

Fig. 4 Physicochemical characterization of the fabricated scaffolds. a Porosity range of the scaffolds. b Density of the fabricated scaffolds. c Swelling percentage of Ha.Col1.Cs (non-cross-linked and crosslinked) scaffolds at different soaking time: (left) swelling percentage of scaffold composition on the overall water uptake and (right) swell-

for AF-MSCs. After 5 days a uniform interconnection of MSC network on the scaffolds as well as multiple cell-cell contacts were visualized (Figs. 5A9, 6A6). At day 10, we observed the AF-MSC confluency was more than $90 \%$ in the presence of Ha.Col1.Cs-IR (Fig. 6A11), Ha.Col1.Cs-DHT (Fig. 6A14) and Ha.Col1.Cs-HEMA (Fig. 6A13) indicating

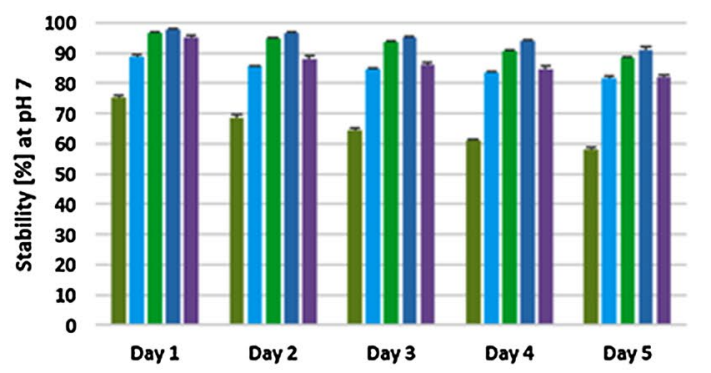

$=$ HaCol1Cs $\equiv$ HaCol1Cs-DHT $\equiv$ HaCol1Cs-lR $\equiv$ HaCol1Cs-GTA $\equiv$ HaCol1Cs-HEMA

ing percentage of scaffold material itself. d Enzymatic degradation studies of Ha.Col1.Cs (non-cross-linked and cross-linked) scaffolds. e Mechanical strength. f Stabilities of Ha.Col1.Cs scaffolds (non-crosslinked and cross-linked) in aqueous solution: (left) stability test at $\mathrm{pH}$ 4.0 and (right) stability test at $\mathrm{pH} 7.0$

no negative effect on proliferation. We also noticed that cells adapted to Ha.Coll.Cs-GTA with time, allowing growth of the surviving cells (Fig. 6A12).

Regarding in vitro mineralization in the presence of MSCs, we observed that clusters of MSCs aggregated together around the scaffolds particles and formed boney-like 
A
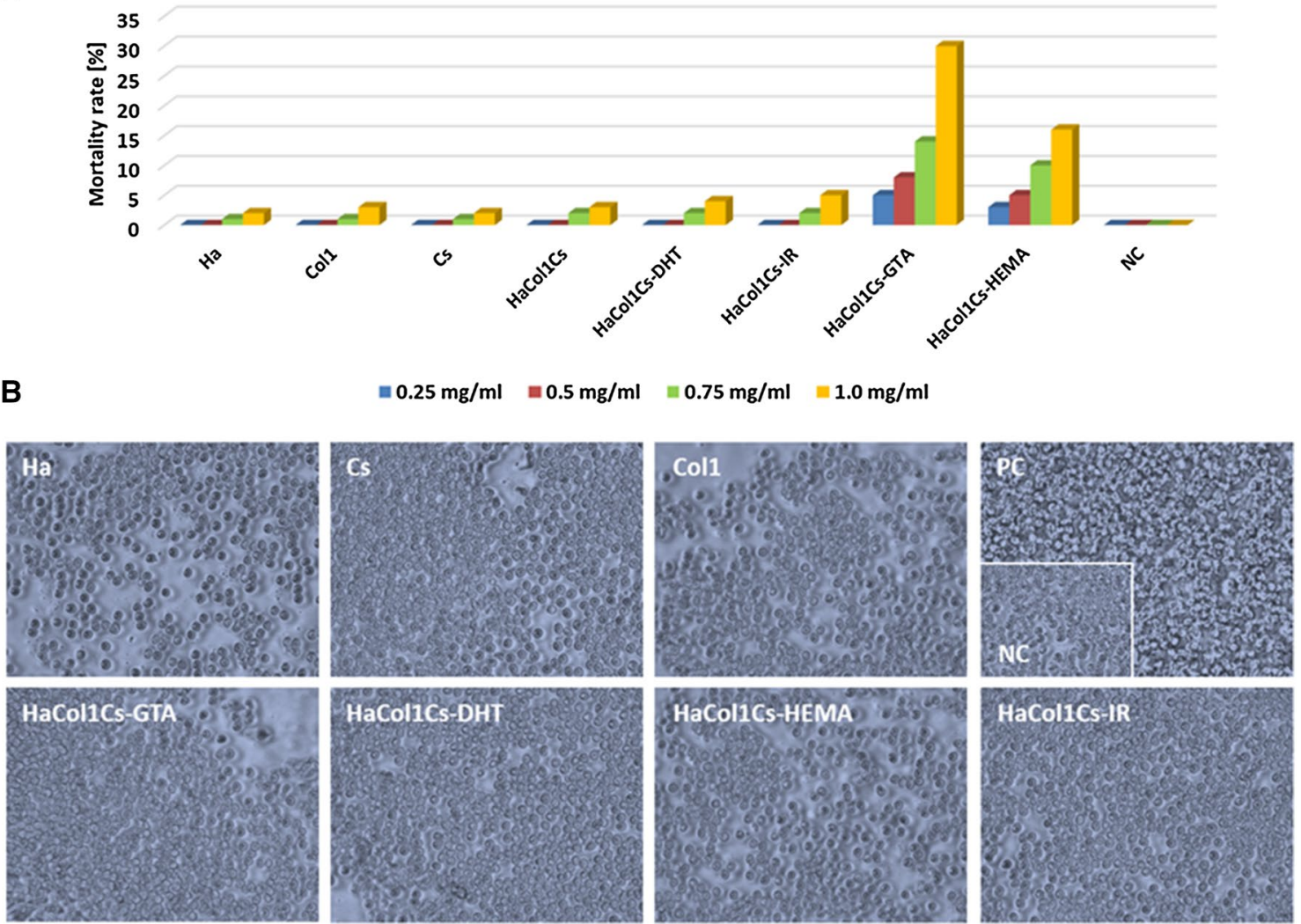

Fig. 5 In vitro cytotoxicity and human blood biocompatibility of Ha.Col1·Cs scaffolds and its constituents. a Brine shrimp lethality assay. b RBC hemolysis biocompatibility assay. PC positive control, and distilled water served as NC negative control

structure (Fig. 6B1-B5). Calcium phosphate deposition by the AF-MSCs was also evidenced by Alizarin Red staining (ARS) in the presence of scaffolds at day 21(Fig. 6B6-B10). An enhanced mineral deposition was found for the composite of Ha.Coll-Cs-IR and Ha.Col1.Cs-DHT compared to Ha·Coll·Cs-HEMA (Fig. 6B6, B9).

\section{In vivo grafting of Ha.Col1.Cs-IR and Ha.Col1.Cs-DHT into a rabbit mandible defect model}

Based on the physicochemical and in vitro biological tests, $\mathrm{Ha} \cdot \mathrm{Col1} \cdot \mathrm{Cs}-\mathrm{IR}$ and $\mathrm{Ha} \cdot \mathrm{Col1} \cdot \mathrm{Cs}-\mathrm{DHT}$ were qualified as good candidates to be transplanted in a rabbit maxillofacial mandible defect model (Fig. 7a). By $2 \mathrm{~h}$ post-operation, the rabbits appeared to be normal with regards to their eating habits and movements. Furthermore, we did not observe any adverse reactions or post-operative complications such as abnormal bleeding or infection at surgical sites. Further, we did not notice any signs of inflammation such as swelling, and the grafted materials were confirmed to be intact within the defects. However, after 4 weeks, the surgical area of each rabbit was healed with minor scar marks and covered with new hair (Fig. 7B13-B16).

\section{Post-operative histological and radiological analysis}

Hematoxylin and eosin (H\&E) staining was done to access the comparative histology of the experimented mandible bones which were implanted with Ha.Col1.Cs-IR, Ha.Coll.Cs-DHT, human bone graft (gold standard positive control), and defects without transplantations served as a negative control. No significant differences were observed between $\mathrm{Ha} \cdot \mathrm{Col1} \cdot \mathrm{Cs}-\mathrm{DHT}$ and Ha.Col1.Cs-IR concerning the formation of new blood vessels, and new bone structures (Fig. 8a). However, the human bone graft was superior whereas empty controls were inferior when compared to Ha.Col1.Cs-DHT and Ha.Coll.CsIR regarding bone regeneration 4 weeks after transplantation. Representative radiological images of the Ha.Coll.Cs-IR transplanted group revealed the gradual regeneration and filling of the defected rabbit mandible (Fig. 8B1-B4).

\section{Discussion}

All biomaterials used in this study were obtained from bio-waste which would have been discarded. As such we have extracted Ha from bovine cortical bone, Coll from 


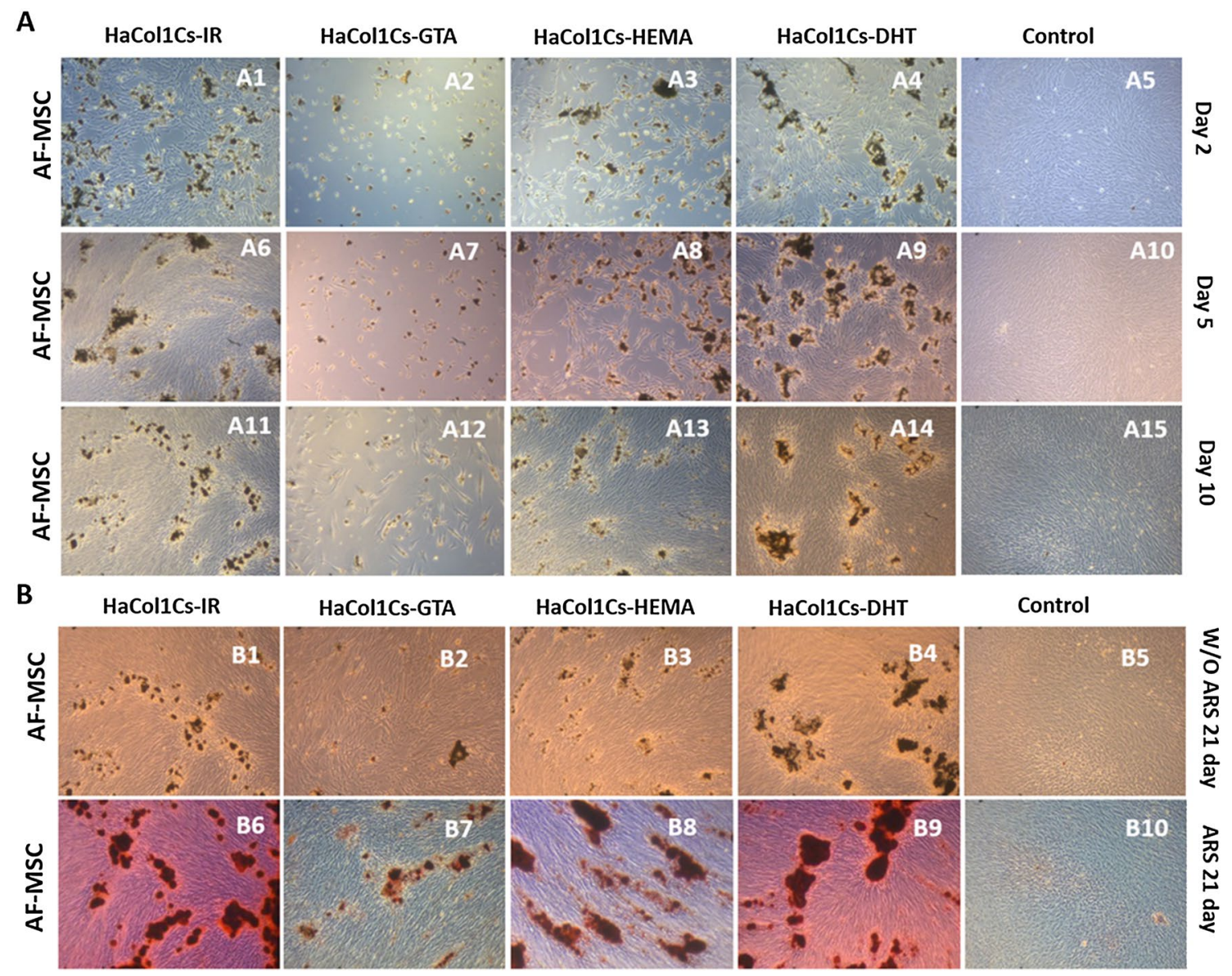

Fig. 6 AF-MSC attachment, growth and mineralization analysis in presence of various $\mathrm{Ha} \cdot \mathrm{Col1} \cdot \mathrm{Cs}$ scaffolds. a AF-MSC attachment and growth in presence of the formulated scaffolds powder. b In vitro mineralization of AF-MSCs in presence of distinct scaffolds. Calcification was evidenced by Alizarin Red (ARS) staining slaughtered rabbit skin and Cs from prawn shell (Fig. 1A1, $\mathrm{B} 1, \mathrm{C} 1)$. Thus, we have used materials and procedures which are a biologically safe and economically desirable (RincónLópez et al. 2018; Pachence 1996; El-Jawhari et al. 2016; Khan et al. 2005, 2012). Recently, these constituents for the fabrication of scaffold gained attention encompassing tunable chemical (molding ability into various geometries and formation of porous structures) and biological (suitable for cell growth and osteo-conduction) properties (Wang et al. 2017; Dan et al. 2016; Qasim et al. 2017; Zhang et al. 2013; Demirtaş et al. 2017; Chamieh et al. 2016; Balagangadharan et al. 2017).

In line with our FTIR analysis (Fig. 2a), the major band of the amide I in cross-linked Ha-Coll sample was focused at $1653 \mathrm{~cm}^{-1}$ and minor bands at 1636 and $1663 \mathrm{~cm}^{-1}$ (Boskey et al. 1999; Epaschalis et al. 2001). In general, no significant changes were observed in the mineral phase of the scaffold due to radiation; however, new bonds ( $\mathrm{C}-\mathrm{N}$ triple bond and $\mathrm{C}-\mathrm{C}$ triple bond) were formed in the polymer phase (Fig. 2c). Due to the irradiation, bonds could be formed between the polypeptide chains without utilizing the acidic and basic side chains which control the pore structure. Since, cellular attachment and infiltration are significantly affected by the scaffolds' mean pore size (Murphy et al. 2010); we have measured this parameter by SEM. The mean pore diameter for all scaffolds was found to range from 98 to $204 \mu \mathrm{m}$ (Fig. 3), which is similar to pore sizes reported for other microparticle-based scaffolds $(100-800 \mu \mathrm{m})$ (Reves et al. 2009) and above the required minimum size $(50 \mu \mathrm{m})$ as needed for osteogenesis (Cheung et al. 2015).

In this study, Ha.Coll.Cs scaffolds were fabricated by thermally induced phase separation technique (Fig. 1e) with good porosity (90.64-96.21\%) and water absorption capacity (Fig. 4a, c). The measured porosity reached the recommended porosity of $\geq 90 \%$ for bone substitute materials to accommodate osteoblasts or osteoprogenitor cells (Sabir et al. 2002). Therefore, this scaffold was qualified to be good penetrable by cell suspensions, required nutrient, metabolites, and soluble signals. The density of the fabricated scaffold ranged from 0.28 to $0.38 \mathrm{~g} / \mathrm{cm}^{3}$ (Fig. 4b), whereas the 

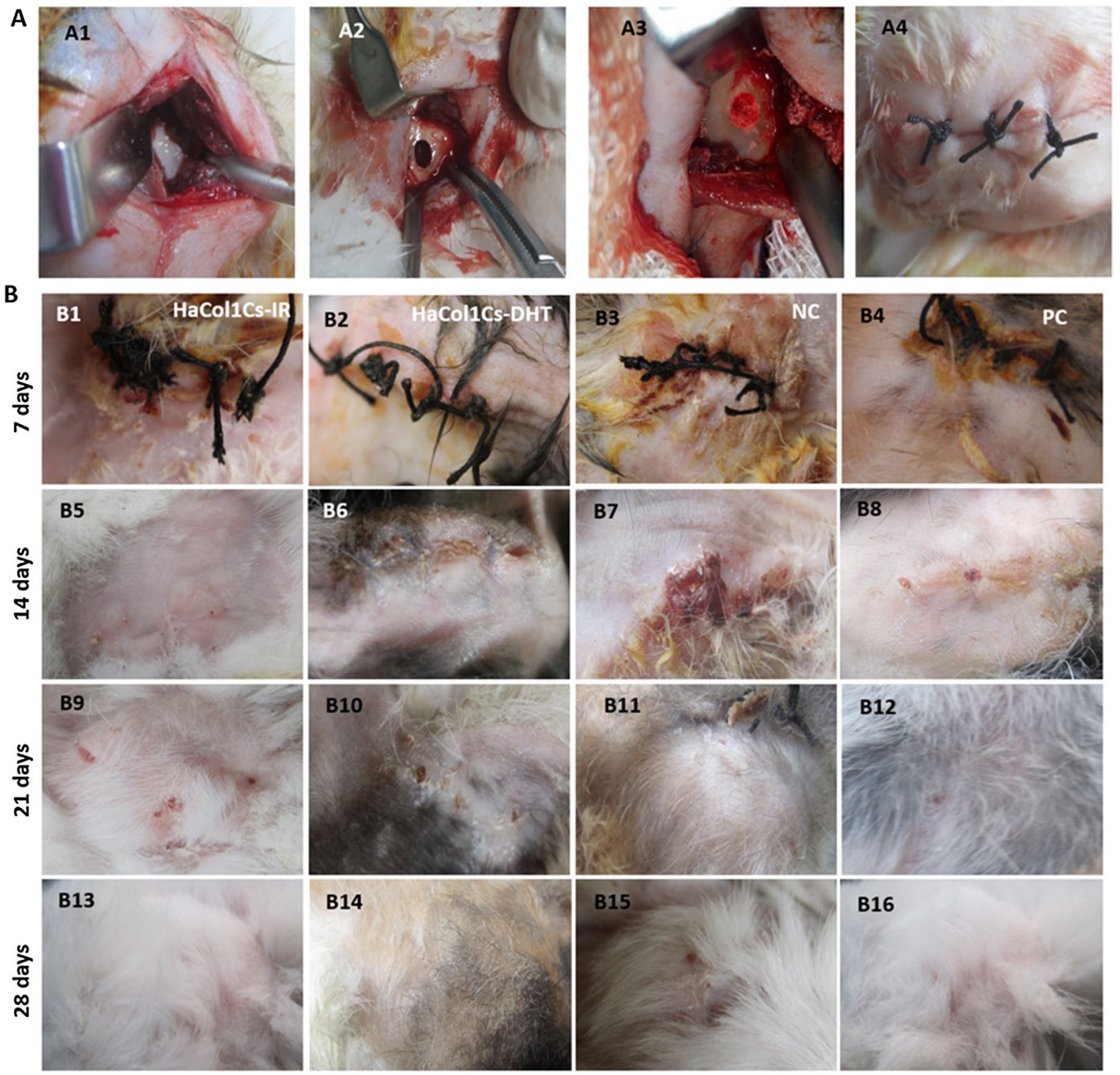

Fig. 7 In vivo grafting of scaffold in the surgically created rabbit maxillofacial mandible defect (non-load bearing) model. a Surgical and implantation procedures. (A1) Surgical incision showed the site

apparent density of trabecular bone was reported to range from 0.14 to $1.10 \mathrm{~g} / \mathrm{cm}^{3}$ (Evans et al. 1992).

The swelling ability depends on the microstructure and hydrophilic nature of the scaffold (Yan et al. 2010). Since Col1 and Cs are both hydrophilic materials, the fabricated scaffolds were shown to have a relevant swelling ability which is in favor of maintaining the porous structure (Chen et al. 2016). The scaffolds without cross-linker showed relatively lower stability than the cross-linked Ha.Coll $\cdot$ Cs scaffolds (Fig. 4f). It was also revealed that the stability of the $\mathrm{Ha} \cdot \mathrm{Col1} \cdot \mathrm{Cs}$ scaffolds was reduced in acidic condition which has been shown before (Khan et al. 2012). We could show that cross-linking had a profound effect on the mechanical stability of the scaffold. Ha.Col1.Cs-DHT showed the best strength amongst the cross-linked scaffolds (Fig. 4e). of mandible to be drilled. (A2) Drilled defect chamber in the mandible of rabbits. (A3) Defect filled with scaffold. (A4) Sutured incision. b Post-grafting recovery observation from day 7 to day 28

Different studies also presented similar compressive strength in the hydroxyapatite-collagen scaffold and showed that the compressive strength of the collagen scaffold was increased by de-hydrothermal treatment (Kozlowska and Sionkowska 2015; Nitzsche et al. 2010).

One feature of a good bone scaffold is that the scaffold and its degradation products should not provoke an inflammatory response (Velasco et al. 2015; Alaribe et al. 2016). The degradation rate of porous scaffold influences cell vitality, cell growth, and even host response (She et al. 2008; Tan et al. 2007). In our study, the biodegradation was best for Ha.Coll.Cs without cross-linking and varied between the different cross-linker methods (Fig. 2e) whereas $\mathrm{Ha} \cdot \mathrm{Col} 1 \cdot \mathrm{Cs}-\mathrm{DHT}$ was better degradable than the others. Aqueous mixtures of collagen and chitosan form 


\section{A}
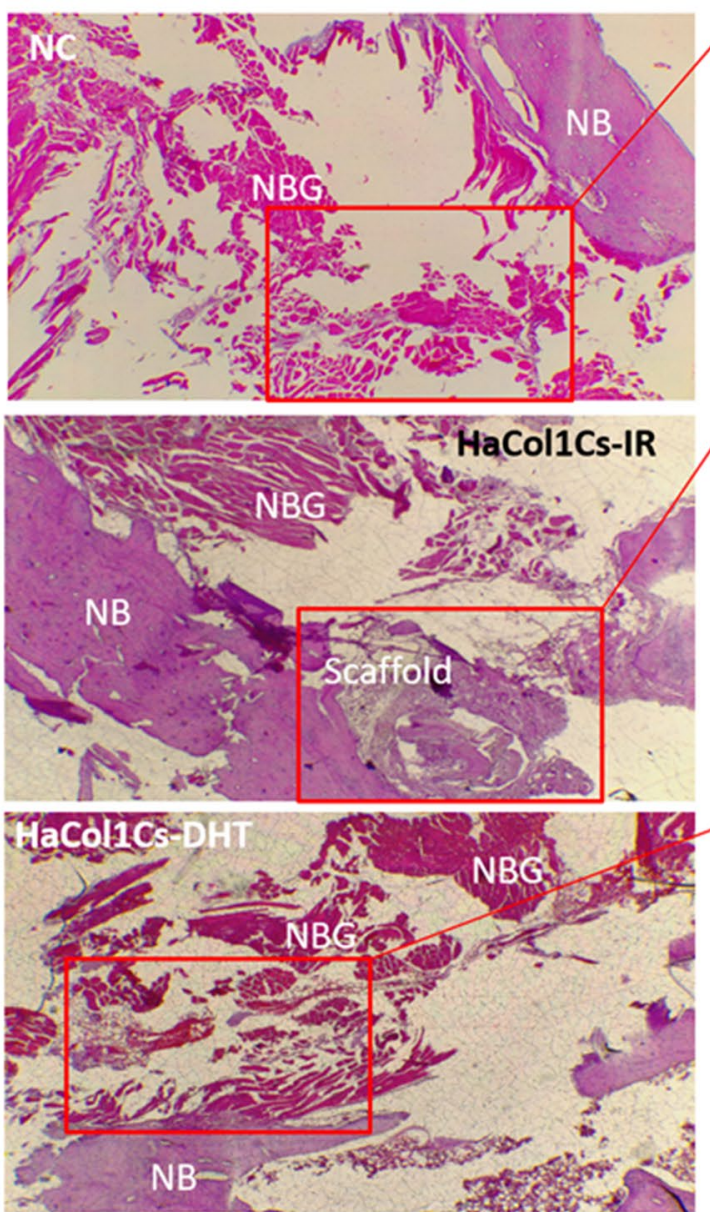

B
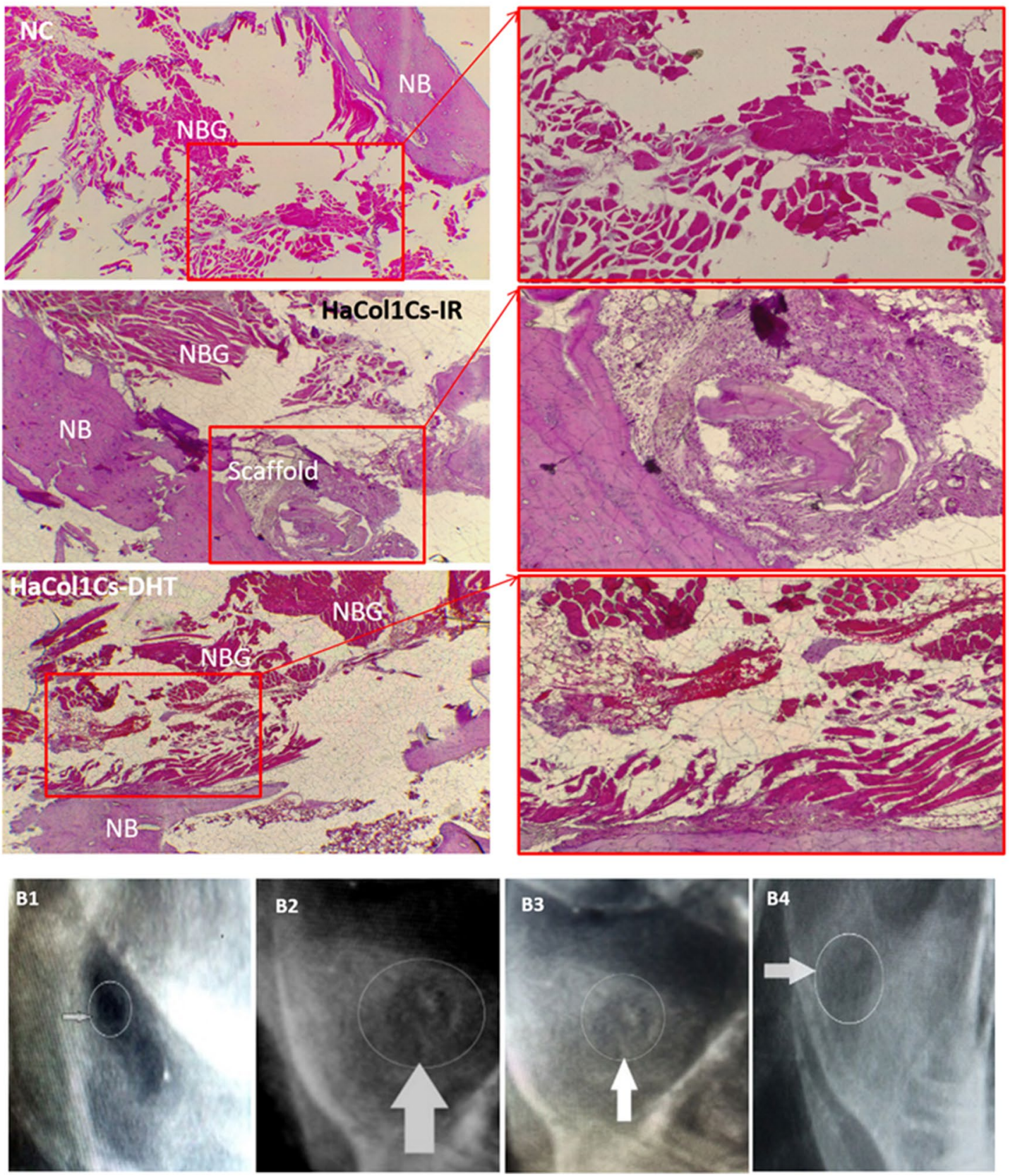

Fig. 8 Post-operative histological and radiological analysis. a Histological analyses of the treated defects after 4 months. Defected mandible without any implant/graft (first lane), Ha.Col1.Cs-IR (second lane), and $\mathrm{Ha} \cdot \mathrm{Col1} \cdot \mathrm{Cs}-\mathrm{DHT}$ (third lane) whereas native bone (NB)

electrostatic interactions between positively charged amino groups and negatively charged carboxyl groups leading to a complex structure (Taravel and Domard 1996; Khan et al. 2012). Cross-linking with DHT is supposed to cause the formation of new amide bonds in protein-based materials (Geiger et al. 2003). For this reason, it seems evident that DHT makes collagen more resistant to enzymatic degradation (Wahl and Czernuszka 2006). and newly bone growth (NBG) are distinguished. b Representative radiological images during the recovery period in the Ha.Col1.Cs-IR group from (B1) day 1 to (B4) 4 months

The Ha.Col1.Cs-IR exhibited a lower biodegradability than $\mathrm{Ha} \cdot \mathrm{Coll} \cdot \mathrm{Cs}-\mathrm{DHT}$ which may be due to the crosslinking method in which high-energy ionizing radiation or photoinitiator molecules are used. This method eventually influences the mechanical properties and degradation behavior of irradiated collagen-based scaffolds (Davidenko et al. 2015; Hovakimyan et al. 2012; Lew et al. 2007). 
Our extracted Ha, Col1 and Cs were RBC biocompatible and non-toxic to brine shrimp larvae, which qualify these as biomaterial precursors for scaffold preparation (Khan et al. 2012; Levengood and Zhang 2014). Furthermore, we observed $\mathrm{Ha} \cdot \mathrm{Coll} \cdot \mathrm{Cs}-\mathrm{IR}$ and $\mathrm{Ha} \cdot \mathrm{Col1} \cdot \mathrm{Cs}-\mathrm{DHT}$ were compatible for AF-MSCs attachment and growth (Fig. 6A1, A4) which may be due to Col1 which is widely used as a coating material and constituent of scaffolds supporting cell attachment (Cooke et al. 2008; Wang et al. 2017; Zhang et al. 2013).

Ha.Col1.Cs-GTA inhibited cell attachment and growth of AF-MSCs (Fig. 6A2, A12). Previously it has been reported that adipose-derived stem cells attached and grew slowly in presence of a GTA-sponge (Yang et al. 2018). Although GTA is a widely used chemical cross-linker, it was reported that the functional aldehyde groups of GTA are toxic for cells (Oryan et al. 2014) and may cause significant biohazard problems, which has limited its application in commercial products (Yoo et al. 2011).

Alizarin red staining provided a proof that the AFMSCs formed calcium-based mineral deposits around the scaffolds at day 21(Fig. 6b). Mineralization was reported to be induced by the osteoconductive nano-Ha powder present in the composites (Zhang et al. 2014; O'Brien 2011). In line with our work, chitosan-gelatin/nanohydroxyapatite scaffolds have been shown to support MC3T3-E1 cell attachment, proliferation, and mineralization (Dan et al. 2016).

At cellular level, the composite scaffold acts as an impermanent matrix for cell proliferation until new bone tissue is completely regenerated (Wattanutchariya and Changkowchai 2014). In vivo compatibility and utility of $\mathrm{Ha} \cdot \mathrm{Col} 1 \cdot \mathrm{Cs}-\mathrm{IR}$ and Ha.Coll.Cs-DHT were evaluated (Fig. 7). We observed that both compatible contributed to mandible bone restoration. This regeneration capacity was superior to non-treatment of the defect but was inferior to the gold standard bone graft (Fig. 8). In line with our study, it was previously demonstrated that the nHAC/PLGA scaffolds implanted rabbit critical-size mandible defect possessed tissue compatibility and higher bone restoration capacity compared to empty controls (Wang et al. 2017).

Here, we did not add any growth factors, or cells to the scaffolds. By addition of bone-marrow MSCs to nanohydroxyapatite/collagen/poly L-lactide scaffolds total bone formation in a rabbit critical-size mandibular bone defect model was significantly higher than without the addition of stem cells (Wang et al. 2016). Therefore, for optimal bone healing, a combination of stem cells and biomaterials was reported to be needed to treat periodontal bone defects (Wang et al. 2017), suggesting the necessities of additional studies including mesenchymal cells. Additionally, more studies should aim to reveal the regulatory mechanisms involved in the complex process of biomineralization in vivo.

\section{Conclusion}

We have successfully fabricated Ha.Col1.Cs scaffolds from low cost and locally available polymeric bioactive materials using thermally induced phase separation technique with the cross-linkers such as GTA, DTH, IR and HEMA. All four formulated scaffolds showed substantial physicochemical and morphological features. Preliminary in vitro tests on AF-MSCs identified Ha.Col1.Cs-DHT and Ha.Col1.CsIR scaffolds as the most competent materials. In vivo, Ha.Col1.Cs-IR and Ha.Col1.Cs-DHT scaffolds significantly supported new bone formation in a maxillofacial mandible defect model making these scaffolds promising for the use in treatment of bone defects. However, 3D porous scaffold design, in vivo transplantation and clinical applications are still requiring significant improvement to harness optimum applicability. In-depth understanding of the basic fabrication processes involved and the post-transplantation mechanisms may help to achieve clinical relevance.

Acknowledgements The authors acknowledge the support from CRP (IAEA Research Contract no. 18343/R1), International Atomic Energy Agency, Austria. Prof. Dr. James Adjaye acknowledges support from the Medical Faculty, Heinrich Heine University Düsseldorf and Mr. Md. Shaifur Rahman acknowledges support from the German Academic Exchange Service (DAAD-91607303).

Author contributions MSR, MMR, LSS,NA, SMA, NC, JTC and JA conceived the idea. MMR, MSR, NA, and LSS designed and performed the experimental work and analyses the data. JTC analyzed the physical characterization of the scaffold and scaffold constituents data. MZH performed the in vitro brine shrimp cytotoxicity and RBC hemolysis assay. MMR, MSR, MZH and LSS wrote the manuscript. NC, SMA, JTC and JA edited the manuscript. NC, SMA and JA supervised the work. All the authors read and approved the final manuscript.

Funding For the purchasing of lab instruments and reagents, funds had been provided by the International Atomic Energy Agency, Austria (CRP Contract no. 18343/R1). No funding has been obtained for publication charge. The funding agency did not have any contribution on experimental idea, design, work, manuscript writing, and publication.

\section{Compliance with ethical standards}

Conflict of interests The authors declare that they have no competing interest.

Ethics approval The study was conducted according to the protocol approved by ethical committee of the Atomic Energy Research Establishment, Bangladesh and ethical committee of the Jahangirnagar University, Bangladesh. Post-slaughter bovine bone and rabbit skin were collected for research purpose from the healthy animals. AF-MSC samples from healthy human donors were collected during full-term C-sections from the Obstetrics and Gynaecology faculty, Heinrich Heine University Düsseldorf, Germany, with the patient informed consent as well as institutional ethical approval.

Consent for publication All the authors have agreed to publish the data in your esteemed Journal. 
Availability of data and materials The data and materials have been presented in the main manuscript and can be given upon request.

Open Access This article is distributed under the terms of the Creative Commons Attribution 4.0 International License (http://creativeco mmons.org/licenses/by/4.0/), which permits unrestricted use, distribution, and reproduction in any medium, provided you give appropriate credit to the original author(s) and the source, provide a link to the Creative Commons license, and indicate if changes were made.

\section{References}

Alaribe FN, Manoto SL, Motaung SCKM (2016) Scaffolds from biomaterials: advantages and limitations in bone and tissue engineering. Biologia 71(4):353-366. https://doi.org/10.1515/biolo g-2016-0056

Baino F, Novajra G, Vitale-Brovarone C (2015) Bioceramics and scaffolds: a winning combination for tissue engineering. Front Bioeng Biotechnol 3:202. https://doi.org/10.3389/fbioe.2015.00202

Balagangadharan K, Dhivya S, Selvamurugan N (2017) Chitosan based nanofibers in bone tissue engineering. Int J Biol Macromol 104(PtB):1372-1382. https://doi.org/10.1016/j.ijbiomac.2016.12.046

Boskey AL, Wright TM, Blank RD (1999) Collagen and bone strength. J Bone Miner Res 14:330-335

Calabrese G, Giuffrida R, Forte S, Fabbi C, Figallo E, Salvatorelli L, Memeo L, Parenti R, Gulisano M, Gulino R (2017) Human adipose-derived mesenchymal stem cells seeded into a collagenhydroxyapatite scaffold promote bone augmentation after implantation in the mouse. Sci Rep 7:7110. https://doi.org/10.1038/s4159 8-017-07672-0

Chamieh F, Collignon AM, Coyac BR, Lesieur J, Ribes S, Sadoine J, Llorens A, Nicoletti A, Letourneur D, Colombier ML, Nazhat SN, Bouchard P, Chaussain C, Rochefort GY (2016) Accelerated craniofacial bone regeneration through dense collagen gel scaffolds seeded with dental pulp stem cells. Sci Rep 6:38814. https ://doi.org/10.1038/srep38814

Chen JS, Tu SL, Tsay RY (2010) A morphological study of porous polylactide scaffolds prepared by thermally induced phase separation. J Taiwan Inst Chem Eng 41(2):229-238

Chen Z, Du T, Tang X, Liu C, Li R, Xu C, Tian F, Du Z, Wu J (2016) Comparison of the properties of collagen-chitosan scaffolds after $\gamma$-ray irradiation and carbodiimide cross-linking. J Biomater Sci Polym Ed 27(10):937-953. https://doi.org/10.1080/09205 063.2016.1169478

Cheung RCF, Ng TB, Wong JH, Chan WY (2015) Chitosan: an update on potential biomedical and pharmaceutical applications. Laurienzo P, ed. Mar Drugs 3(8):5156-5186. https://doi.org/10.3390/ md13085156

Cooke MJ, Phillips SR, Shah DS, Athey D, Lakey JH, Przyborski SA (2008) Enhanced cell attachment using a novel cell culture surface presenting functional domains from extracellular matrix proteins. Cytotechnology 56(2):71-79. https://doi.org/10.1007/ s10616-007-9119-7

Croisier F, Jérôme C (2013) Chitosan-based biomaterials for tissue engineering. Eur Polym J 49(4):780-792. https://doi. org/10.1016/j.eurpolymj.2012.12.009

d'Aquino R, De Rosa A, Lanza V, Tirino V, Laino L, Graziano A, Desiderio V, Laino G, Papaccio G (2009) Human mandible bone defect repair by the grafting of dental pulp stem/progenitor cells and collagen sponge biocomplexes. Eur Cell Mater 12(18):75-83

Dan Y, Liu O, Liu Y, Zhang YY, Li S, Feng XB, Shao ZW, Yang C, Yang SH, Hong JB (2016) Development of novel biocomposite scaffold of chitosan-gelatin/nanohydroxyapatite for potential bone tissue engineering applications. Nanoscale Res Lett 11:487. https ://doi.org/10.1186/s11671-016-1669-1

Davidenko N, Bax DB, Schuster CF, Farndale RW, Hamaia SW, Best SM, Cameron RE (2015) Optimization of UV irradiation as a binding site conserving method for crosslinking collagen-based scaffolds. J Mater Sci Mater Med 27:14. https://doi.org/10.1007/ s10856-015-5627-8

Degen T, Sadki M, Bron E, König U, Nénert G (2014) The high score suite. Powder Diffr 29(S2):S13-S14

Demirtaş TT, Irmak G, Gümüşderelioğlu M (2017) A bioprintable form of chitosan hydrogel for bone tissue engineering. Biofabrication 9(3):035003. https://doi.org/10.1088/1758-5090/aa7b1d

Echazú MIA, Tuttolomondo MV, Foglia ML, Mebert AM, Alvarez GS, Desimone MF (2016) Advances in collagen, chitosan and silica biomaterials for oral tissue regeneration: from basics to clinical trials. J Mater Chem B 4:6913-6929. https://doi. org/10.1039/C6TB02108E

El-Jawhari JJ, Sanjurjo-Rodríguez C, Jones E, Giannoudis PV (2016) Collagen-containing scaffolds enhance attachment and proliferation of non-cultured bone marrow multipotential stromal cells. J Orthop Res 34(4):597-606. https://doi.org/10.1002/jor.23070

Epaschalis EP, Verdelis K, Dotty SB, Boskey AL, Mendelsohn R, Yamauchi M (2001) Spectroscopic characterization of collagen crosslinks in bone. J Bone Miner Res 16(10):1821-1828

Evans LA, Macey DJ, Webb J (1992) Calcium biomineralization in the regular teeth of the chiton, acanthopleura hirtosa. Calcif Tissue Int 51:78-82

Gaihre B, Uswatta S, Jayasuriya AC (2017) Reconstruction of craniomaxillofacial bone defects using tissue-engineering strategies with injectable and non-injectable scaffolds. J Funct Biomater 8(4):49. https://doi.org/10.3390/jfb8040049

Geiger M, Li RH, Friess W (2003) Collagen sponges for bone regeneration with rhBMP-2. Adv Drug Deliv Rev 55:1613-1629

Gravel M, Gross T, Vago R, Tabrizian M (2006) Responses of mesenchymal stem cell to chitosan-coralline composites microstructured using coralline as gas forming agent. Biomaterials 27(9):1899-1906. https://doi.org/10.1016/j.biomateria 1s. 2005.10 .020

Greenwald MA, Kuehnert MJ, Fishman JA (2012) Infectious disease transmission during organ and tissue transplantation. Emerg Infect Dis 18(8):e1. https://doi.org/10.3201/eid1808.120277

Hovakimyan M, Guthoff RF, Stachs O (2012) Collagen cross-linking: current status and future directions. J Ophthalmol 2012:406850. https://doi.org/10.1155/2012/406850

Khan MA, Ferdous S, Mustafa AI (2005) Improvement of physicomechanical properties of chitosan films by photo-curing with acrylic monomers. J Polym Environ 13(2):193-201

Khan MN, Islam JMM, Khan MA (2012) Fabrication and characterization of gelatin-based biocompatible porous composite scaffold for bone tissue engineering. J Biomed Mater Res, Part A 100(11):3020-3028. https://doi.org/10.1002/jbm.a.34248

Kim BS, Kang HJ, Yang SS, Lee J (2014) Comparison of in vitro and in vivo bioactivity: cuttlefish-bone-derived hydroxyapatite and synthetic hydroxyapatite granules as a bone graft substitute. Biomed Mater 9(2):025004. https://doi.org/10.1088/17486041/9/2/025004

Kozłowska J, Sionkowska A (2015) Effects of different crosslinking methods on the properties of collagen-calcium phosphate composite materials. Int J Biol Macromol 74:397-403

Kukhareva LV, Shamolina II, Polevaia EV (2010) Method of preparation of tissue engineering and cell cultivation collagen by acid extraction of calf skin. Tsitologiia 52(7):597-602

Kumar A, Nune KC, Misra RD (2016) Biological functionality of extracellular matrix-ornamented three-dimensional printed 
hydroxyapatite scaffolds. J Biomed Mater Res A 104(6):13431351. https://doi.org/10.1002/jbm.a.35664

Levengood SL, Zhang M (2014) Chitosan-based scaffolds for bone tissue engineering. J Mater Chem B Mater Biol Med 2(21):31613184. https://doi.org/10.1039/C4TB00027G

Lew DH, Liu PH, Orgill DP (2007) Optimization of UV cross-linking density for durable and nontoxic collagen GAG dermal substitute. J Biomed Mater Res B Appl Biomater 82(1):51-56

Maisani M, Pezzoli D, Chassande O, Mantovani D (2017) Cellularizing hydrogel-based scaffolds to repair bone tissue: how to create a physiologically relevant micro-environment? J Tissue Eng 8:1-26

Maji K, Dasgupta S, Pramanik K, Bissoyi A (2016) Preparation and evaluation of gelatin-chitosan-nanobioglass 3D porous scaffold for bone tissue engineering. Int J Biomater 2016:9825659. https ://doi.org/10.1155/2016/9825659

Mao AS, Mooney DJ (2015) Regenerative medicine: current therapies and future directions. Proc Natl Acad Sci USA 112(47):1445214459. https://doi.org/10.1073/pnas.1508520112

Markvardsen AJ, Shankland K, David WIF, Johnston JC, Ibberson RM, Tucker M, Nowell H, Griffin T (2008) ExtSym: a program to aid space-group determination from powder diffraction data. J Appl Crystallogr J Appl Cryst 41(6):1177-1181

Murphy CM, Haugh MG, O'Brien FJ (2010) The effect of mean pore size on cell attachment, proliferation and migration in collagen glycosaminoglycan scaffolds for tissue engineering. Biomaterials 31:461-466

Nagahama H, Rani VV, Shalumon KT, Jayakumar R, Nair SV, Koiwa S, Furuike T, Tamura H (2009) Preparation, characterization, bioactive and cell attachment studies of alpha-chitin/gelatin composite membranes. Int J Biol Macromol 44(4):333-337. https://doi. org/10.1016/j.ijbiomac.2009.01.006

Nitzsche H, Lochmann A, Metz H, Hauser A, Syrowatka F, Hempel E, Müller T, Thurn-Albrecht T, Mäder K (2010) Fabrication and characterization of a biomimetic composite scaffold for bone defect repair. J Biomed Mater Res A 94(1):298-307

O'Brien FJ (2011) Biomaterials and scaffolds for tissue engineering. Mater Today 14:88-95

Oryan A, Alidadi S, Moshiri A, Maffulli N (2014) Bone regenerative medicine: classic options, novel strategies, and future directions. J Orthop Surg Res 9(1):18. https://doi.org/10.1186/1749-799X-9-18

Pacak CA, MacKay AA, Cowan DB (2014) An improved method for the preparation of type I collagen from skin. J Vis Exp 83:51011. https://doi.org/10.3791/51011

Pachence JM (1996) Collagen-based devices for soft tissue repair. J Biomed Mater Res 33(1):35-40

Pallela R, Venkatesan J, Janapala VR, Kim SK (2012) Biophysicochemical evaluation of chitosan hydroxyapatite-marine sponge collagen composite for bone tissue engineering. J Biomed Mater Res, Part A 100(2):486-495. https://doi.org/10.1002/jbm.a.33292

Polo-Corrales L, Latorre-Esteves M, Ramirez-Vick JE (2014) Scaffold design for bone regeneration. J Nanosci Nanotechnol 14(1):15-56

Qasim SB, Najeeb S, Delaine-Smith RM, Rawlinson A, Ur Rehman I (2017) Potential of electrospun chitosan fibers as a surface layer in functionally graded GTR membrane for periodontal regeneration. Dent Mater 33(1):71-83. https://doi.org/10.1016/j.denta 1.2016.10.003

Rahman MS, Spitzhorn LS, Wruck W, Hagenbeck C, Balan P, Graffmann N, Bohndorf M, Ncube A, Guillot PV, Fehm T, Adjaye J (2018) The presence of human mesenchymal stem cells of renal origin in amniotic fluid increases with gestational time. Stem Cell Res Ther 9:113. https://doi.org/10.1186/s13287-018-0864-7

Reves BT, Bumgardner JD, Cole JA, Yang Y, Haggard WO (2009) Lyophilization to improve drug delivery for chitosan-calcium phosphate bone scaffold construct: a preliminary investigation. J Biomed Mater Res B Appl Biomater 90(1):1-10. https://doi. org/10.1002/jbm.b.31390
Rincón-López JA, Hermann-Muñoz JA, Giraldo-Betancur AL, De Vizcaya-Ruiz A, Alvarado-Orozco JM, Muñoz-Saldaña J (2018) Synthesis, characterization and in vitro study of synthetic and bovine-derived hydroxyapatite ceramics: a comparison. Materials 11(3):333. https://doi.org/10.3390/ma11030333

Rodríguez-Vázquez M, Vega-Ruiz B, Ramos-Zúñiga R, SaldañaKoppel DA, Quiñones-Olvera LF (2015) Chitosan and its potential use as a scaffold for tissue engineering in regenerative medicine. Biomed Res Int. https://doi.org/10.1155/2015/82127 9 (Article ID 821279)

Sabir MI, Xu X, Li L (2002) A review on biodegradable polymeric materials for bone tissue engineering applications. J Mater Sci 44(21):5713-5724

She Z, Zhang B, Jin C, Feng Q, Xu Y (2008) Preparation and in vitro degradation of porous three-dimensional silk fibroin/chitosan scaffold. Polym Degrad Stab 93(7):1316-1322

Sofronia AM, Baies R, Anghel EM, Marinescu CA, Tanasescu S (2014) Thermal and structural characterization of synthetic and natural nanocrystalline hydroxyapatite. Mater Sci Eng C Biol Appl 43:153-163. https://doi.org/10.1016/j.msec.2014.07.023

Spitzhorn LS, Rahman MS, Schwindt L, Ho HT, Wruck W, Bohndorf M, Wehrmeyer S, Ncube A, Beyer I, Hagenbeck C, Balan P, Fehm T, Adjaye J (2017) Isolation and molecular characterization of amniotic fluid-derived mesenchymal stem cells obtained from caesarean sections. Stem Cells Int 2017:5932706. https:// doi.org/10.1155/2017/5932706

Tan H, Gong Y, Lao L, Mao Z, Gao C (2007) Gelatin/chitosan/ hyaluronan ternary complex scaffold containing basic fibroblast growth factor for cartilage tissue engineering. J Mater Sci Mater Med 18(10):1961-1968

Taravel MN, Domard A (1996) Collagen and its interactions with chitosan III. Some biological and mechanical properties. Biomaterials 17(4):451-455

Tollemar V, Collier ZJ, Mohammed MK, Lee MJ, Ameerde GA, Reid RR (2016) Stem cells, growth factors and scaffolds in craniofacial regenerative medicine. Genes Diseases 3(1):56-71. https:// doi.org/10.1016/j.gendis.2015.09.004

Tong S, Xu DP, Liu ZM, Du Y, Wang XK (2016a) Synthesis and in vitro and in vivo evaluation of a novel TGF- $\beta 1$-SF-CS threedimensional scaffold for bone tissue engineering. Int J Mol Med 38(2):367-380. https://doi.org/10.3892/ijmm.2016.2651

Tong S, Xu DP, Liu ZM, Du Y, Wang XK (2016b) Synthesis of the new-type vascular endothelial growth factor-silk fibroinchitosan three-dimensional scaffolds for bone tissue engineering and in vitro evaluation. J Craniofac Surg 27(2):509-515. https ://doi.org/10.1097/SCS.0000000000002296

Velasco MA, Narváez-Tovar CA, Garzón-Alvarado DA (2015) Design, materials, and mechanobiology of biodegradable scaffolds for bone tissue engineering. Biomed Res Int 2015:729076. https://doi.org/10.1155/2015/729076

Wahl DA, Czernuszka JT (2006) Collagen-hydroxyapatite composites for hard tissue repair. Eur Cell Mater 11:43-56

Wang X, Xing H, Zhang G, Wu X, Zou X, Feng L, Wang D, Li M, Zhao J, Du J, Lv Y, Lingling E, Liu H (2016) Restoration of a critical mandibular bone defect using human alveolar bone-derived stem cells and porous nano-HA/collagen/ PLA scaffold. Stem Cells Int 2016:8741641. https://doi. org/10.1155/2016/8741641

Wang X, Wu X, Xing H, Zhang G, Shi Q, Lingling E, Liu N, Yang T, Wang D, Qi F, Wang L, Liu H (2017) Porous nanohydroxyapatite/collagen scaffolds loading insulin PLGA particles for restoration of critical size bone defect. ACS Appl Mater Interfaces 9(13):11380-11391. https://doi.org/10.1021/acsami.6b13566

Wattanutchariya W, Changkowchai W (2014) Characterization of porous scaffold from chitosan-gelatin/hydroxyapatite for bone grafting. proceedings of the international multi conference of 
engineers and computer scientists, vol 2, IMECS March 12-14, 2014, Hong Kong

Wua SC, Hsua HC, Hsua SK, Changb YC, Ho WF (2016) Synthesis of hydroxyapatite from egg shell powders through ball milling and heat treatment. J Asian Ceram Soc 4(1):85-90

Yan LP, Wang YJ, Ren L, Wu G, Caridade SG, Fan JB, Wang LY, Ji PH, Oliveira JM, Oliveira JT, Mano JF, Reis RL (2010) Genipincross-linked collagen/chitosan biomimetic scaffolds for articular cartilage tissue engineering applications. J Biomed Mater Res A 96a:465-475

Yang X, Lu Z, Wu H, Li W, Zheng L, Zhao J (2018) Collagen-alginate as bioink for three-dimensional (3D) cell printing based cartilage tissue engineering. Mater Sci Eng C Mater Biol Appl 83:195-201. https://doi.org/10.1016/j.msec.2017.09.002

Yi H, Rehman FU, Zhao C, Liu B, He N (2016) Recent advances in nano scaffolds for bone repair. Bone Res 4:16050

Yoo JS, Kim YJ, Kim SH, Choi SH (2011) Study on genipin: a new alternative natural crosslinking agent for fixing heterograft tissue. Korean J Thorac Cardiovasc Surg 44(3):197-207
Yu B, Zhang Y, Li X, Wang Q, Ouyang Y, Xia Y, Yu B, Lin B, Li S, Fan Y, Chen Y (2013) The use of injectable chitosan/nanohydroxyapatite/collagen composites with bone marrow mesenchymal stem cells to promote ectopic bone formation in vivo. J Nanomater 2013:506593

Zhang X, Xu M, Liu X, Zhang F, Wei Y, Meng S, Dai X, Duan A, Deng X (2013) Restoration of critical-sized defects in the rabbit mandible using autologous bone marrow stromal cells hybridized with nano- $\beta$-tricalcium phosphate/collagen scaffolds. J Nanomater 2013:913438. https://doi.org/10.1155/2013/913438

Zhang X, Li XW, Li JG, Sun XD (2014) Preparation and mechanical property of a novel 3D porous magnesium scaffold for bone tissue engineering. Mater Sci Eng C Mater Biol Appl 42:362-367

Publisher's Note Springer Nature remains neutral with regard to jurisdictional claims in published maps and institutional affiliations. 